\title{
Vanadyl spin qubits 2D arrays and their integration on superconducting resonators
}

\author{
Ainhoa Urtizberea, ${ }^{a, b,{ }^{*}}$ Eva Natividad, ${ }^{a}$ Pablo J. Alonso, ${ }^{a}$ Laura Pérez-Martínez, ${ }^{a, c}$ Miguel A. \\ Andrés, ${ }^{\mathrm{a}, \mathrm{c}}$ Ignacio Gascón, ${ }^{\mathrm{a}, \mathrm{c}}$ Ignacio Gimeno, ${ }^{\mathrm{a}}$ Fernando Luis ${ }^{\mathrm{a}}$ and Olivier Roubeau, ${ }^{\mathrm{a},{ }^{*}}$ \\ ${ }^{a}$ Instituto de Ciencia de Materiales de Aragón (ICMA), CSIC and Universidad de Zaragoza, Plaza San Francisco s/n, 50009 Zaragoza, Spain \\ e-mail: roubeau@unizar.es. \\ ${ }^{b}$ Centro Universitario de la Defensa, 50090 Zaragoza, Spain \\ e-mail: ainhoa@unizar.es.
}

${ }^{c}$ Instituto de Nanociencia de Aragón (INA), Universidad de Zaragoza, 50018 Zaragoza, Spain

Vanadyl systems have been shown to possess superior quantum coherence among molecular spin qubits. Meanwhile two-dimensional (2D) networks of spin qubit nodes could provide the means to achieve the control of qubit localization and orientation required for implementation of molecular spin qubits in hybrid solidstate devices. Here, the 2D metal-organic framework $\left[\{\mathrm{VO}(\mathrm{TCPP})\} \mathrm{Zn}_{2}\left(\mathrm{H}_{2} \mathrm{O}\right)_{2}\right]_{\infty}$ is reported and its vanadyl porphyrin node is shown to exhibit superior spin dynamics and to enable coherent spin manipulations, making it a valid spin qubit candidate. Nanodomains of the MOF 2D coordination planes are efficiently formed at the air-water interface, first under Langmuir-Schaefer conditions, allowing mono- and multiple layer deposits to be transferred to a variety of substrates. Similar nanodomains are then successfully formed in-situ on the surface of $\mathrm{Nb}$ superconducting coplanar resonators. Transmission measurements with a resonator with a 14 mm-wide constriction allow to estimate that the single spin-photon coupling $G_{1}$ of the vanadyl spins in the nanodomains is close to being optimal, at ca. $0.5 \mathrm{~Hz}$. Altogether, these results provide the basis for developing a viable hybrid quantum computing architecture.

\section{Introduction}

Using the quantum mechanical properties of certain materials to enable quantum information processing promises fundamental and applied advances in theoretical chemistry, biology, physics or cryptography. ${ }^{1}$ While small-scale quantum processors with few to tens of quantum bits (qubits) are being developed thanks to recent staggering efforts, more powerful machines will be necessary that involve much larger numbers, and this scalability remains a daunting challenge for the currently used technologies. $^{2}$ The electron spin carried by paramagnetic molecules has been proposed as an alternative embodiment of qubits, ${ }^{3}$ with the advantages that it can be manipulated through pulsed microwaves and that huge amount of identical qubits are obtained in one sole reaction. Another advantage is the ability of molecules to embody

\section{Conceptual insights}

We report a method to integrate molecular spin qubits with controlled orientation and maintained quantum coherence onto superconducting resonators. The resulting solid-state device provides a viable hybrid architecture to engineer a quantum computer. The electronic spin of paramagnetic molecules has arisen as an alternative embodiment of qubits, with advantages in terms of scalability and tuneability. Improved coherence times have recently been reported, in particular using molecules with a vanadyl spin carrier. These however still need to be wired up individually to an electronic device while maintaining their quantum coherence. To reach this goal, the strategy used in this work relies on vanadyl porphyrin nodes able to build a bidimensional metalorganic framework (MOF). In the solid-state, the vanadyl qubits nodes exhibit superior coherence up to ambient temperature and their quantum manipulation is demonstrated. Nanosheets of the 2D MOF can be formed interfacially at the air-water interface, including in-situ on $\mathrm{Nb}$ superconducting lines. The periodicity of the rigid network ensures an homogeneous and controlled orientation and environment for the vanadyl qubit nodes. The coupling of the molecular qubits to a quantum cavity estimated through transmission measurements is close to being optimal, showing the used strategy allows optimizing the crucial qubit-cavity interface, and thus opens a viable route towards a hybrid quantum computation architecture.

various qubits and therefore perform quantum gate operations or even algorithms such as error correction codes, either through multiple quantum levels ${ }^{4}$ or through various forms of multiple spin carriers. ${ }^{5}$ The lifetime of the superpositions of quantum states providing the qubit definition, or coherence time $T_{2}$, of the first studied molecular spin qubits was relatively low, ${ }^{6}$ but synthetic chemistry has offered the means to adjust factors at the origin of decoherence. ${ }^{7}$ This has indeed allowed significant improvement of molecular qubits $T_{2}$ or phasememory times $\left(T_{\mathrm{M}}\right.$, with $\left.T_{2} \geq T_{\mathrm{M}}\right)$, with record values now being $68 \mu$ s for diluted solids ${ }^{8}$ and even $700 \mu$ s for frozen solutions. ${ }^{9}$ While these results remain exceptional, there is now hope that the coherence of molecular qubits will be sufficient to implement quantum manipulations.

Another key aspect is the scalable manipulation of qubits, for which there is so far no solution. Contrary to what has been recently argued with a 3D Metal-Organic Frameworks (MOFs) of qubits, ${ }^{10}$ scaling is not just disposing of an infinite number of 
qubits. One has to be able to read and/or manipulate them, independently. ${ }^{11}$ Inspired by related developments in coupling superconducting qubits to circuit quantum electrodynamics, one proposed technology to do this is to couple each molecular qubit to an electronic device. ${ }^{12}$ The design and feasibility of a hybrid magnetic quantum processor consisting of individual molecular spins coupled to superconducting coplanar resonators have recently been examined. ${ }^{13}$ For its realization, it is key that molecular spin qubits be implemented at specific positions of devices, more specifically that one qubit be strongly coupled to nanoscale constriction(s) of superconducting lines. It also appears relevant to control the orientation of the molecular qubit with respect to the superconductor surface, so that the different qubits energy gaps would not be significantly different, nor depart from their expected values. ${ }^{13}$ These requirements are not likely to be easily satisfied by traditional grafting of isolated molecules. Indeed, most wet chemistry grafting methods applied to isolated magnetic molecules typically make use of functionalization of either the surface or the molecule with a chemical function at the end of a flexible arm. This normally results in variable and uncontrolled orientation and inhomogenous surface density. ${ }^{14}$ UHV techniques do lead to highly ordered surface nanostructures, but the resulting strong interaction with the substrate may lead to modifications of the qubit electronic levels, as observed for vanadyl phtalocyanine molecules sublimed on superconducting $\mathrm{Pb}{ }^{15}$ We have recently shown that a valid alternative to these approaches is to form nanodomains of flat $2 \mathrm{D}$ networks of qubit nodes. ${ }^{16}$ Adjusting dilution with diamagnetic nodes would then allow to reach the necessary ratio of one qubit per constriction. This was done using a $\mathrm{Cu}(\mathrm{II})$ porphyrin building block bearing four carboxylic groups, $\{\mathrm{Cu}(\mathrm{TCPP})\} \quad\left(\mathrm{H}_{6} \mathrm{TCPP}=5,10,15,20-\right.$ tetrakis(4-carboxyphenyl)-porphyrin). $^{16}$ The 2D MOF $\left[\{\mathrm{Cu}(\mathrm{TCPP})\} \mathrm{Zn}_{2}\left(\mathrm{H}_{2} \mathrm{O}\right)_{2}\right]_{\infty}, 1^{\mathrm{Cu}}$, built by coordination with diamagnetic $\mathrm{Zn}^{\prime \prime}$ ions could be formed as nanosheets at the air-water interface. Considering the superior coherence properties observed for vanadyl systems, ${ }^{17}$ a $2 \mathrm{D}$ analogue to $1^{\mathrm{Cu}}$ with this spin carrier appears particularly appealing. However, while $\mathrm{H}_{6}$ TCPP has been used to form a wealth of $3 \mathrm{D}$ frameworks in which a pillaring ligand connects $2 \mathrm{D}$ planes formed through the 4-connecting node TCPP, ${ }^{18}$ only one involves a vanadyl center, PPF-5(VO). ${ }^{19}$ It has actually been recently re-examined to evaluate its quantum coherence. ${ }^{10} \mathrm{On}$ the other hand, the number of reported structures with similar 2D planes without pillars is extremely scarce. The 2D MOF $1^{\mathrm{Cu}}$ in fact only adds to three other related structurally characterized systems. ${ }^{20,21,22}$ We report here on its vanadyl analogue $\left[\{\mathrm{VO}(\mathrm{TCPP})\} \mathrm{Zn}_{2}\left(\mathrm{H}_{2} \mathrm{O}\right)_{2}\right]_{\infty}, \mathbf{1}^{\text {vo }}$, demonstrating that its $\mathrm{V}^{\mathrm{IV}}$ spins have superior spin dynamics with respect to those in PPF-5(VO) or $\mathbf{1}^{\mathrm{Cu}}$, while being amenable to coherent manipulations. Besides showing the $1^{\text {vo }}$ MOF can also be formed as $2 \mathrm{D}$ nanosheets, and transferred to a variety of substrate, we also go a step further towards the implementation of these qubits nanodomains by succeeding in their in-situ formation on the surface of the same superconducting transmission lines used to develop the mentioned resonators, allowing for the first nanoscale estimation of the associated coupling.

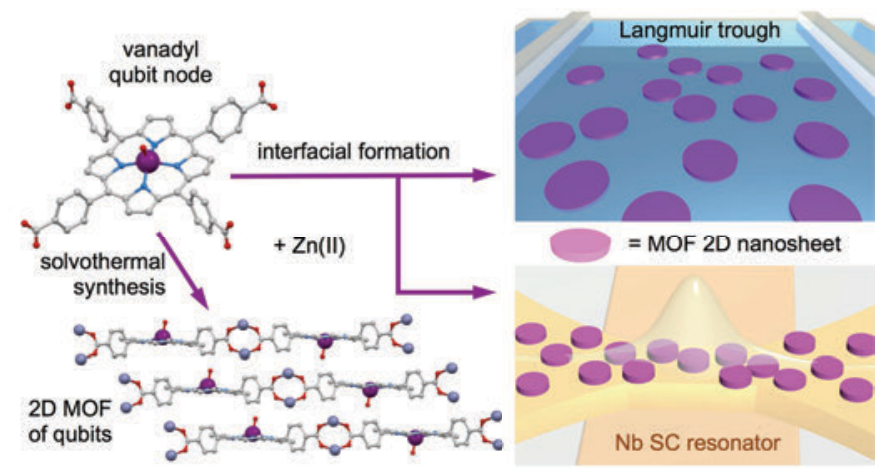

Scheme 1. Bulk and interfacial formation of the 2D MOF $\left[\{\mathrm{VO}(\mathrm{TCPP})\} \mathrm{Zn}_{2}\left(\mathrm{H}_{2} \mathrm{O}\right)_{2}\right]_{\infty}$.

\section{Experimental}

\subsection{Materials synthesis.}

Commercial 5,10,15,20-tetrakis(4-carboxyphenyl)porphine $\left(\mathrm{H}_{6} \mathrm{TCPP},>97 \%\right)$ was purchased from $\mathrm{TCl}$. $\mathrm{VO}\left(\mathrm{SO}_{4}\right) \cdot \mathrm{H}_{2} \mathrm{O}$ (>99.0\%), $\mathrm{ZnCl}_{2}(>98 \%), \mathrm{Zn}\left(\mathrm{NO}_{3}\right)_{2} \cdot 6 \mathrm{H}_{2} \mathrm{O}(98 \%)$, glacial acetic acid and Reagent/HPCL grade solvents N,N'dimethylformamide (dmf), chloroform, dichloromethane, ethanol and methanol were purchased from Aldrich and used without further purification.

Synthesis of [VO( $\left.\left.\mathrm{H}_{4} \mathrm{TCPP}\right)\right]$ precursor. First the ethyl-ester [VO $\left(\mathrm{H}_{4}\right.$ TCPPEt $\left.)\right]$ was synthesized adapting the conditions used previously for the $\mathrm{Cu}$ analogue. ${ }^{23,24}$ For this, $\mathrm{H}_{6}$ TCPP (81 $\mathrm{mg}, 0.10 \mathrm{mmol}), \mathrm{VO}\left(\mathrm{SO}_{4}\right) \cdot \mathrm{H}_{2} \mathrm{O}(17 \mathrm{mg}, 0.094 \mathrm{mmol})$ and 10 $\mathrm{mL}$ ethanol were gently mixed in a $23 \mathrm{~mL}$ Teflon-lined PARR acid digestion bomb, and the operation repeated 5 times. The five bombs were placed in an oven at $60^{\circ} \mathrm{C}$, warmed to $180^{\circ} \mathrm{C}$ and kept at this temperature for $24 \mathrm{~h}$. After cooling to RT, large shiny violet crystals were recovered by filtration, washed with little ethanol and dried in air. The total yield of crystals of [VO $\left.\left(\mathrm{H}_{4} \mathrm{TCPPEt}\right)\right]$ was $422 \mathrm{mg}(77 \%$ based on vanadyl, 0.436 $\mathrm{mmol})$. The identity and homogeneity of the crystals was confirmed by single-crystal and powder X-ray diffraction and mass spectroscopy (MALDI-TOF-MS matrix: $\mathrm{CHCA}, \mathrm{m} / \mathrm{z}=$ 967.6). Then, $320 \mathrm{mg}$ [VO $\left.\left(\mathrm{H}_{4} \mathrm{TCPPEt}\right)\right](0.33 \mathrm{mmol})$ were dissolved in dichloromethane/methanol $(120 / 13.5 \mathrm{~mL})$, and 15 $\mathrm{mL}$ of a $1 \mathrm{M}$ methanol $\mathrm{NaOH}$ solution were added to the redviolet solution. After stirring at RT for $18 \mathrm{~h}$, the purple solids suspended and deposited on the sides of the flask were recovered by filtration, washed with little chloroform and dissolved in $400 \mathrm{~mL}$ deionized water. $11 \mathrm{~mL}$ glacial acetic acid were then added to the dark purple aqueous solution, resulting in the formation of an immediate purple precipitate. After $2 \mathrm{~h}$ stirring, the purple solid was recovered by filtration over a 0.45 $\mathrm{mm}$ PVDF membrane, washed with little water and dried in air. The total yield of $\left[\mathrm{VO}\left(\mathrm{H}_{4} \mathrm{TCPP}\right)\right]$ powder was $181 \mathrm{mg}(64 \%$ based on [VO(TCPPEt)], $0.21 \mathrm{mmol}$ ). Anal. calcd. for (found): 
C, 67.29 (67.5); H, 3.41 (3.5); N, 6.54 (6.6) weight \%. m/z (MALDI-TOF-MS in $\mathrm{MeOH} / \mathrm{CHCl}_{3}$, matrix: DTCB): 855.3.

\section{Synthesis of $\quad\left[\{\mathrm{VO}(\mathrm{TCPP})\} \mathrm{Zn}_{2}\left(\mathrm{H}_{2} \mathrm{O}\right)_{2}\right] \cdot \mathrm{dmf} \quad\left(1^{\mathrm{VO}}\right)$.} [VO( $\left.\left.\mathrm{H}_{4} \mathrm{TCPP}\right)\right] \quad(18.1 \mathrm{mg}, 0.021 \mathrm{mmol}), \mathrm{Zn}\left(\mathrm{NO}_{3}\right)_{2} \cdot 6 \mathrm{H}_{2} \mathrm{O}(24.3$ $0.082 \mathrm{mmol}$ ) and $10 \mathrm{~mL} \mathrm{dmf}$ were put into a $23 \mathrm{~mL}$ Teflonlined PARR acid digestion bomb. The bomb was warmed in an oven to $124^{\circ} \mathrm{C}$, kept at this temperature for $50 \mathrm{~h}$ and cooled down slowly to room temperature. A polycrystalline purple powder was recovered by filtration, washed with little $\mathrm{dmf}$, little acetone and dried in air. The total yield of $1^{\mathrm{VO}}$ was $20.5 \mathrm{mg}$ $\left(90 \%\right.$ based on [VO $\left.\left.\left(\mathrm{H}_{4} \mathrm{TCPP}\right)\right], 0.019 \mathrm{mmol}\right)$. Anal. calcd. for $\mathrm{VZn}_{2} \mathrm{C}_{51} \mathrm{H}_{35} \mathrm{~N}_{5} \mathrm{O}_{12}$ (found): C, 56.06 (56.3); $\mathrm{H}, 3.32$ (3.5); N, 6.41 (6.5) weight \%. The synthesis was repeated several times with similar yield. The relative $\mathrm{V}: \mathrm{Zn}$ metal content was determined by ICP-AES and repeatedly found to be 0.47 , slightly below the expected value of 0.50 . This may indicate that a very partial demetallation of the $\left[\mathrm{VO}\left(\mathrm{H}_{4} \mathrm{TCPP}\right)\right]$ precursor has occurred, which would agree with magnetic properties (see main text).

The same synthetic conditions were used to form a 100 -fold magnetically diluted analogue $1{ }^{\mathrm{vO}}{ }_{1 \%}$, albeit using [VO $\left.\left(\mathrm{H}_{4} \mathrm{TCPP}\right)\right]$ (0.3 mg, $\left.0.00035 \mathrm{mmol}\right), \mathrm{H}_{6} \mathrm{TCPP}(14.4 \mathrm{mg}$, $0.018 \mathrm{mmol})$ and $\mathrm{Zn}\left(\mathrm{NO}_{3}\right)_{2} \cdot 6 \mathrm{H}_{2} \mathrm{O}(26.9 \mathrm{mg}, 0.091 \mathrm{mmol})$. Under these conditions, the excess zinc nitrate allows full metallation of all TCPP. ${ }^{22}$ The $\mathrm{V}: \mathrm{Zn}$ metal content determined by ICP-AES agrees with the formulation $\left[\{\mathrm{VO}(\mathrm{TCPP})\}_{0.01}\left\{\mathrm{Zn}\left(\mathrm{H}_{2} \mathrm{O}\right)(\mathrm{TCPP})\right\}_{0.99} \mathrm{Zn}_{2}\left(\mathrm{H}_{2} \mathrm{O}\right)_{2}\right]_{\infty}$.

Langmuir and Langmuir-Schaefer film fabrication. Surface pressure-area $(\pi-A)$ isotherms were obtained using a Teflon Langmuir trough NIMA model 702 (dimensions $720 \mathrm{~mm} \times 100$ $\mathrm{mm}$ ). Langmuir-Schaefer films were made with a KSV-NIMA trough model KN 2003, with dimensions of $580 \mathrm{~mm} \times 145 \mathrm{~mm}$. In both cases, compression was performed by a symmetric double-barrier system at constant speed of $7.5 \mathrm{~cm}^{2} \cdot \mathrm{min}^{-1}$. These troughs are housed in a clean room inside closed cabinets and the room temperature is maintained at $293 \mathrm{~K}( \pm 1$ $\mathrm{K})$. Ultra-pure Milli-Q water $(\rho=18.2 \mathrm{M} \Omega \cdot \mathrm{cm})$ was employed to prepare the $\mathrm{ZnCl}_{2}$ solutions used as subphase. $\mathrm{A} \mathrm{ZnCl}_{2}$ subphase with $0.1 \mathrm{M}$ concentration was used, as surface pressure-area $(\pi-A)$ isotherms then provided a molecular area in agreement with those reported for the $\mathrm{H}_{6} \mathrm{TCPP} / \mathrm{CuCl}_{2}$ system. ${ }^{16}$ Solutions of $\left[\mathrm{VO}\left(\mathrm{H}_{4} \mathrm{TCPP}\right)\right](0.1 \mathrm{mM})$ and $\mathrm{H}_{6}$ TCPP $(0.11 \mathrm{mM})$ were prepared by dissolving respectively $2.07 \mathrm{mg}$ and $2.05 \mathrm{mg}$ in $25 \mathrm{~mL}$ of a chloroform/methanol mixture (3:1, $\mathrm{v} / \mathrm{v})$. In a Langmuir-Schaefer experiment procedure, the trough was carefully cleaned with acetone and chloroform, and ultimately filled with Ultra-Pure Milli-Q water, removed by vacuuming, before filling it with $0.1 \mathrm{M} \mathrm{ZnCl}_{2}$ solution. The subphase was then carefully cleaned by closing the barriers down to $40 \mathrm{~mm}$ distance and mild surface-touch vacuuming intra-barriers area. After opening the barriers to the maximum area, the system was let to equilibrium for 5 minutes. The porphyrin solution was carefully spread drop-by-drop onto the subphase using a Hamilton microsyringe held very close to the subphase surface, and left to evaporate for 20 minutes before starting the compression. Substrates (quartz, Mylar) were cleaned by $15 \mathrm{~min}$ ultrasonication, successively in chloroform, acetone and ethanol. Transfers were carried out by horizontal-dipping at a surface pressure of $5 \mathrm{mN} \cdot \mathrm{m}^{-1}$, the substrate being approached to the surface at $0.2 \mathrm{~mm} \cdot \mathrm{min}^{-1}$ and raised at $10 \mathrm{~mm} \cdot \mathrm{min}^{-1}$. Between successive transfers, the substrates were cleaned by gently flushing with Milli-Q water, submerging in Milli-Q water for $3 \mathrm{~min}$, and drying under a $\mathrm{N}_{2}$ flush, to remove unreacted or physisorbed components.

\subsection{Transmission measurements with on-chip resonators.}

Superconducting on-chip coplanar resonators were fabricated on $500 \mu \mathrm{m}$ thick C-plane sapphire wafers. They consist of a $150 \mathrm{~nm}$ thick niobium layer deposited by radio frequency sputtering and then patterned by photolithography and reactive ion etching. ${ }^{25}$ The geometry of the resonators used in the present experiments gives an empty resonator frequency $\mathrm{w}_{\mathrm{r}} / 2 \pi \approx 1.34 \mathrm{GHz}$ and a zero-field quality factor $\mathrm{Q} \approx 10^{4}$, which is mainly limited by intrinsic losses. ${ }^{26}$ The microwave transmission measurements were done using a programmable network analyser at $4.2 \mathrm{~K}$ by mounting the devices on a homemade probe and submerging them in liquid helium inside the bore of a $9 \mathrm{~T} \times 1 \mathrm{~T} \times 1 \mathrm{~T}$ superconducting vector magnet. The magnetic field was applied parallel to the plane of the device, in order to minimize the formation of superconducting vortices in the $\mathrm{Nb}$ film, which damp the resonances and introduce additional noise associated with flux quanta fluctuations. ${ }^{27}$ Fits of the resonances measured at each magnetic field allow extracting $Q$ and $\omega_{r}$ as a function of magnetic field, both of which are expected to be affected by the coupling to spins when a spin transition becomes closer in energy to $\hbar \omega_{r}$.

The coupling of the vanadyl spins with the superconducting resonator $G_{N}$ was determined using the field dependence of the photon decoherence rate and the expression for cases where the coupling $G_{N}$ is much smaller than the decay rate $\mathrm{G}:{ }^{28}$

$$
\kappa=\kappa_{0}+\frac{G_{N}^{2} \Gamma}{\left(\omega_{r}-\omega_{d}\right)+\Gamma^{2}}
$$

where $\omega_{\mathrm{d}}$ is the driving frequency (corresponding to the applied microwave field). Fits of the experimental maxima observed in $\kappa=f\left(\mu_{0} H\right)$ to a Lorentzian line shape directly give an estimate of $G_{N}$ and $G$.

\subsection{Physical characterization}

IR spectra were acquired on neat samples using a Perkin Elmer Spectrum 100 apparatus equipped with an ATR device.

UV-vis spectra were acquired with a Varian Cary 50 spectrophotometer. For deposits, the substrates were placed so that the film plane was normal to the incident light beam, and spectra were acquired at 3 positions of the substrate. 
Powder X-ray Diffraction. Data were obtained at ambient temperature using a Rigaku D-Max diffractometer equipped with a rotating anode and a graphite monochromator to select the Cu-K $\alpha$ wavelength, through the Servicio General de Apoyo a la Investigación-SAI, Universidad de Zaragoza.

Transmission electron microscopy (TEM) was used to study the interatomic distances of the 2D network of [\{VO(TCPP) $\} Z_{2}$ ] deposits. For this purpose, the nanosheets formed at the air-water interface were transferred at $5 \mathrm{mNm}^{-1}$ directly onto TEM carbon-coated Cu grid, in particular, Carbon Type-B 400 mesh from TED PELLA, INC. The grid was previously placed almost entirely floating over a glass slide, only attached to it by two tiny double-sided bonding tape pieces of the width of the grid border. Observations were done at the Laboratorio de Microscopías Avanzadas (LMA) with a Tecnai F30 instrument working at an acceleration voltage of 200 kV. Fast Fourier Transforms (FFTs) of the acquired images were analyzed to find interatomic distances.

X-ray Photoelectron Spectroscopy (XPS) measurements were performed in a Kratos AXIS SUPRA spectrometer, using a monochromatized Al Ka source (1486.6 eV) at the Laboratorio de Microscopías Avanzadas (LMA). Wide scans were acquired at analyser pass energy of $160 \mathrm{eV}$, whereas high-resolution narrow scans were performed at constant pass energy of $20 \mathrm{eV}$. The spectra were obtained at room temperature. The binding energy $(\mathrm{BE})$ scale was internally referenced to the $\mathrm{C}$ 1s peak ( $\mathrm{BE}$ for $\mathrm{CC}=284.9 \mathrm{eV}$ ).

Atomic Force Microscopy observations were done with a NTEGRA Aura microscope from NT-MDT under ambient conditions, operating in semicontact mode, using NS15/AIBS silicon cantilevers (MikroMasch) with $325 \mathrm{kHz}$ nominal resonance frequency.

Magnetic measurements were performed with a commercial magnetometer equipped with a SQUID sensor hosted by the Physical Measurements Unit of the Servicio General de Apoyo a la Investigación-SAI, Universidad de Zaragoza. The diamagnetic contributions to the susceptibility were corrected using Pascal's constant tables. Direct current $(d c)$ data were collected between 2 and $300 \mathrm{~K}$ with an applied field of $100 \mathrm{Oe}$ and at low temperature up to $5 \mathrm{~T}$. Alternating current $(\mathrm{ac})$ data were collected with an applied field of 4 Oe oscillating at different frequencies in the range $0.1 \leq v \leq 1000 \mathrm{~Hz}$. The mass magnetization of the Mylar substrate was determined experimentally to subtract the corresponding contribution in measurements on the LS40 deposit of [VO(TCPP) $\left.\mathrm{Zn}_{2}\right]$.

Electron Paramagnetic Resonance (EPR) experiments, both continuous wave (CW) and pulsed time domain (TD), were performed with a Bruker Biospin ELEXSYS E-580 spectrometer operating in the X-band, using a gas-flow Helium cryostat for low-temperature experiments. $2 p$ and Inversion Recovery ESE-detected as well as nutation experiments were performed. In these experiments the length of the $\pi / 2$ pulse was, typically, $16 \mathrm{~ns}$ whereas the length of the $\pi$ pulse was 32 ns. The simulated spectra were obtained with the EasySpin program. $^{29}$

\section{Results and Discussion}

\subsection{Synthesis and characterization of the 2D MOF $\left[\{\mathrm{VO}(\mathrm{TCPP})\} \mathrm{Zn}_{2}\left(\mathrm{H}_{2} \mathrm{O}\right)_{2}\right]_{\infty}$.}

To obtain the sought $2 \mathrm{D}$ vanadyl material, similar conditions as those resulting in the $\mathrm{Cu}(\mathrm{II})$ analogue were used. The precursor [VO $\left.\left(\mathrm{H}_{4} \mathrm{TCPP}\right)\right]$ molecule is obtained by hydrolysis of its ethyl ester analogue [VO(TCPPEt)], formed by reaction of vanadyl sulphate and the free-base $\mathrm{H}_{6} \mathrm{TCPP}$ in ethanol under solvothermal condition. ${ }^{23,24}\left[\mathrm{VO}\left(\mathrm{H}_{4} \mathrm{TCPP}\right)\right]$ is then reacted with a slight excess of $\mathrm{Zn}\left(\mathrm{NO}_{3}\right)_{2}$ in DMF under autogeneous pressure, producing in high yield a polycrystalline powder made of tiny plates, identified as $1^{\text {vo }}$ on basis of IR spectra, elemental analysis, PXRD and by comparison with the $\mathrm{Cu}(\mathrm{II})$ analogue $1^{\mathrm{Cu}}$. Modifications of the IR spectrum in the $\mathrm{C}=\mathrm{O}$ and $\mathrm{C}-\mathrm{OH}$ stretchings with respect to $\mathrm{H}_{6} \mathrm{TCPP}$ confirm the carboxylic groups are deprotonated and participate in coordination bonds in $1^{\text {vo }}$ (Figure S1). The appearance of a band typical of aliphatic $v_{\mathrm{C}-\mathrm{H}}$ at $2926 \mathrm{~cm}^{-1}$ also points at the incorporation of DMF, as previously observed for $1^{\mathrm{Cu}} \cdot{ }^{16}$ In fact, the IR spectra of the two materials are virtually identical (Figure S2). A slight defect of $\mathrm{V}$ with respect to $\mathrm{Zn}$ in metal content analysis, with a $0.47 \mathrm{~V} / \mathrm{Zn}$ ratio instead of the expected 0.50 , indicates that very partial demetallation of the [VO $\left.\left(\mathrm{H}_{4} \mathrm{TCPP}\right)\right]$ molecule may have taken place, and that the resulting $\mathrm{H}_{6}$ TCPP have coordinated $\mathrm{Zn}(\mathrm{II})$ ions, as in the synthesis of the $\left[\left\{\mathrm{Zn}\left(\mathrm{H}_{2} \mathrm{O}\right) T C P P\right\} \mathrm{Zn}_{2}\left(\mathrm{H}_{2} \mathrm{O}\right)\right]$ analogue. ${ }^{22}$ This is confirmed by the absence of the $v_{\mathrm{N}-\mathrm{H}}$ and $\delta_{\mathrm{N}-\mathrm{H}}$ bands, respectively at 3309 and $963 \mathrm{~cm}^{-1}$ in the free-base $\mathrm{H}_{6}$ TCPP.

Dilution in a diamagnetic host was achieved with $\{\mathrm{Zn}(\mathrm{TCPP})\}$ nodes formed through metallation during the same reaction, ${ }^{22}$ by using a mixture of $\left[\mathrm{VO}\left(\mathrm{H}_{4} \mathrm{TCPP}\right)\right]$ and free-base $\mathrm{H}_{6}$ TCPP in adequate ratio for a $1-2 \%$ dilution and an excess $\mathrm{Zn}$ salt. The IR spectrum and PXRD patterns of the resulting polycrystalline powder are virtually identical to those of $1^{\mathrm{vo}}$ (Figures S2 and S3). One slight difference found in the IR spectrum is a shift of the band corresponding to metal-porphyrin core at ca. $985 \mathrm{~cm}^{-}$ 1 , confirming the porphyrin rings are metallated, albeit with a different metal ion, $\mathrm{Zn}(\mathrm{II})$. The absence of the $\delta_{\mathrm{N}-\mathrm{H}}$ band in the spectrum confirm the assumption that all porphyrins are metallated and the $\mathrm{V}: \mathrm{Zn}$ ratio of 0.003 agrees with the formulation $\quad\left[\{\text { VOTCPP }\}_{0.01}\left\{\mathrm{Zn}\left(\mathrm{H}_{2} \mathrm{O}\right) T C P P\right\}_{0.99} \mathrm{Zn}_{2}\left(\mathrm{H}_{2} \mathrm{O}\right)_{2}\right]_{\infty}$, $1^{\mathrm{VO}}{ }_{1 \%}$.

The available tiny crystals of $1^{\text {vo }}$ were systematically found to be twinned or stacked. It should be noted that twinning was also present in the only two other $2 \mathrm{D}$ structures reported thus far with TCPP, both obtained only thanks to synchrotron radiation. ${ }^{16,22}$ Unfortunately, here we were unable to resolve the twinning/polycrystal nature, and no acceptable structure could be obtained from repeated single-crystal diffraction 
synchrotron experiments. Nevertheless, the PXRD patterns of $1^{\text {vo }}$ are extremely similar to those of the $\mathrm{Cu}$ (II) analogue for which the crystal structure was determined, pointing at isostructural materials. Contrary to the $\mathrm{Cu}$ analogue, the diluted material $1_{1 \%}^{\text {vo }}$ maintains the same structural phase. In fact, the calculated patterns of a model in which the $\mathrm{Cu}$ (II) ion lying at the center of the porphyrin ring is simply replaced by a vanadyl moiety, with the $\mathrm{V}$ site slightly off the porphyrin plane, match reasonably well the experimental data for both $1^{\text {vo }}$ and $1^{\mathrm{VO}}{ }_{1 \%}$. Although detailed structural aspects cannot be discussed, the same $2 \mathrm{D}$ plane structure and similar packing can be assumed with confidence. The monoclinic structure is made of neutral square grid planes parallel to the $b$ axis and built by connection of the $\{\mathrm{VO}(\mathrm{TCPP})\}$ nodes through $\mathrm{Zn}_{2}(\mathrm{COO})_{4}$ paddle-wheels (Fig. 1 top). The planes are stacked-shifted along the a axis, with an interplane separation of only ca. $5 \AA$ (Fig. 1 bottom), the shortest VO $\cdots V O$ separations being between neighboring planes at ca. $6.6 \AA$, while the shortest in-plane separation of ca. $16.6 \AA$ corresponds to the square diagonal. The vanadyl group is necessarily disordered by symmetry over the two opposite directions in-between planes, possibly relevant for the poor diffraction, and the presence of a distribution of relaxation times (see below).

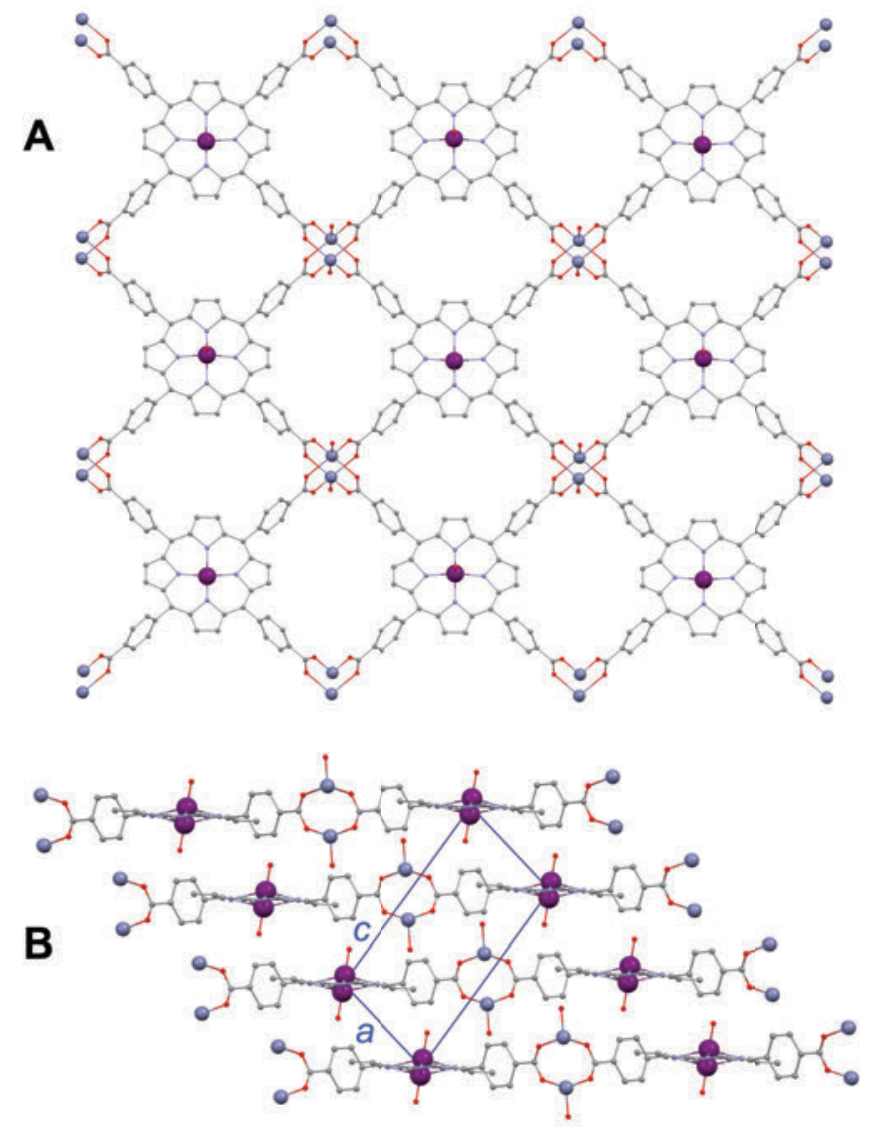

Fig. 1. Two views of the structural model for $1^{\text {vo }}$ based on the $\mathrm{Cu}(\mathrm{II})$ analogue structure and powder diffraction. A, top: the 2D planes formed by VOTCPP nodes connected through $\mathrm{Zn}_{2}$ tetracarboxylate paddle-wheels. $\mathrm{B}$, bottom: packing of the $2 \mathrm{D}$ planes. Note that the two possible orientations of the vanadyl group are shown to highlight this source of structural disorder. Color code: V, violet; Zn, blue-grey; O, red; $\mathrm{N}$, light blue; $\mathrm{C}$, grey. Hydrogens are omitted for clarity.

The continuous wave (CW) X-band EPR spectra of polycrystalline $1^{\text {vo }}$ and $1^{\text {vo }}{ }_{1 \%}$ samples measured at RT are shown in Figure 2 (top traces). No significant variation of the spectra is observed when the temperature changes in the 6$300 \mathrm{~K}$ range. They are associated to a vanadyl entity and both can be described with an axial spin-Hamiltonian ( $\mathrm{SH}$ ) including the electronic Zeeman interaction $\left(g_{\|}=1.969, g_{\perp}=1.99\right)$ and the hyperfine interaction with the $I=7 / 2{ }^{51} \mathrm{~V}$ nucleus $\left(A_{\|}=475\right.$ $\mathrm{MHz}, A_{\perp}=172 \mathrm{MHz}$ ). A comparison between the experimental spectra and the calculated ones using the former $\mathrm{SH}$ parameters is given in both Figures 2 and S9. It is in agreement with the local symmetry at the porphyrin site and the $\mathrm{SH}$ parameters are similar to those found in other vanadyl porphyrins, and in particular to those derived for PPF-5(VO). ${ }^{10}$

The equilibrium magnetic susceptibility $\chi$ of polycrystalline $1^{\text {vo }}$ follows the Curie law down to $2 \mathrm{~K}$ with $C=0.325 \mathrm{~cm}^{3} \mathrm{~mol}^{-1}$ (Figure S4). The relatively low Curie constant $\mathrm{C}$ compared with the expected value of $0.375 \mathrm{~cm}^{3} \mathrm{~mol}^{-1}$ for $\mathrm{g}=2$ likely results from a small fraction of porphyrins coordinated by diamagnetic $\mathrm{Zn}^{\mathrm{Il}}$ ions, due to the potential demetallation of vanadyl porphyrins in coordinating solvent and the fact $\mathrm{H}_{6}$ TCPP would coordinate $\mathrm{Zn}$ (II) ions under the used synthetic conditions demetallated, ${ }^{22}$ and that these are present in excess in the synthesis. The magnetization vs. field data is reasonably well described by the Brillouin function for $\mathrm{g}=1.97$ (Figure S5). Considering the experimentally determined $g_{\text {eff }}$ of 1.981, this would correspond to only ca. $1-2 \%$ of $\left\{\mathrm{Zn}\left(\mathrm{H}_{2} \mathrm{O}\right) T C P P\right\}$ diamagnetic nodes, a somewhat lower fraction than that one would derive from the values of $\chi T$, but most likely more accurate given the much stronger signal detected at low temperatures. Also, this is in line with metal content analysis (see above). On the other hand, the absence of any decrease in the $\chi^{T}$ product at low temperatures indicates no significant magnetic interactions are at work. Therefore, the spins are more isolated in $1^{\mathrm{vo}}$ than in $1^{\mathrm{Cu}}$, for which a weak antiferromagnetic interaction could be estimated. ${ }^{16}$ Although it is unlikely any exchange interaction may propagate through the $\left.\left\{\mathrm{Zn}_{2} \text { (carboxyphenyl }\right)_{2}\right\}$ path, it is relevant that the magnetic orbital in the case of the vanadyl spin is $d_{x y}$, i.e. not pointing towards the pyrrole $\mathrm{N}$-donors, so that no significant spin density is to be expected on the porphyrin ring, contrary to the case of the $\mathrm{Cu}$ analogue. This would mean that the weak antiferromagnetic interaction in the latter is likely propagated through interplane pi $\cdots$ pi interactions. 


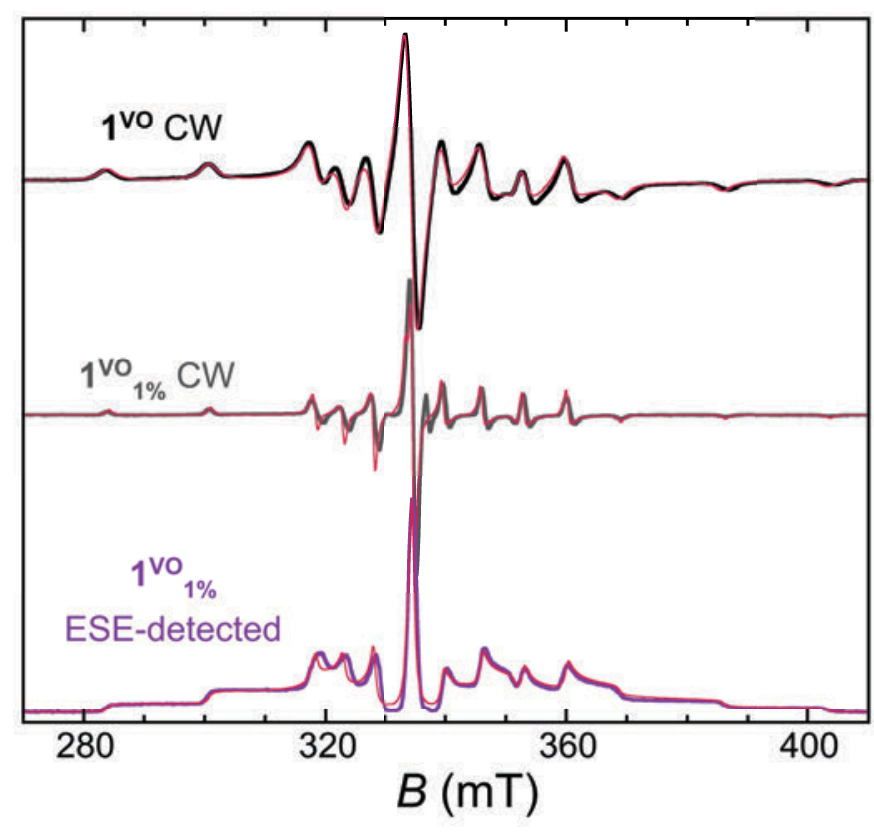

Fig. 2. Top: X-band CW-EPR spectra of $1^{\mathrm{vo}}$ and $1^{\mathrm{vo}}{ }_{1 \%}$ recorded at RT. Bottom: $2 p$-ESE-detected EPR spectrum ( $\tau=200 \mathrm{~ns}$ ) of polycrystalline $1^{\mathrm{vo}}{ }_{1 \%}$ measured at $6 \mathrm{~K}$. The thin red lines are simulations using an axial SH with $g_{\|}=1.969, g_{1}=1.99, A_{\|}=475 \mathrm{MHz}$ and $A_{\perp}=172 \mathrm{MHz}$ (see txt).

\subsection{Spin dynamics and quantum coherence}

Magnetization dynamics were first evaluated through ac magnetic susceptibility measurements on the undiluted material $1^{\text {vo }}$ (Figures S6-S8). No out-of-phase component of the susceptibility $\chi$ " is detected at $1.8 \mathrm{~K}$ in the whole ac field frequency range studied $(0.1-1000 \mathrm{~Hz})$, in agreement with the weak magnetic anisotropy of the vanadyl $S=1 / 2$ spin in $1^{\text {vo }}$, insufficient to produce any significant intrinsic energy barrier to spin reversal. Application of a $d c$ field though results in the onset of slow relaxation of magnetization, with the observation of an out-of-phase component, coinciding with a decreased inphase susceptibility $\chi$ '. For spin $1 / 2$ systems, the associated relaxation time can be taken as a measure of the spin-lattice relaxation time $T_{1}$. Thus $T_{1}{ }^{\text {ac }}$ was determined by fitting the frequency dependence of $\chi$ ' and $\chi$ " to their corresponding generalized Debye model expression (see ESI). The presence of a distribution of relaxation times is clearly indicated by rather broad maxima, the distribution width parameter in the generalized Debye model, $b$, being in the range $0.5-0.85$. The field dependence of $T_{1}$ ac at $1.8 \mathrm{~K}$ was first explored and is depicted in Figure 3. $T_{1}{ }^{\text {ac }}$ first increases at low $d c$ fields to reach a maximum of almost $20 \mathrm{~ms}$ at $0.5 \mathrm{~T}$, and then decreases markedly at fields above $1 \mathrm{~T}$. Above $3 \mathrm{~T}, T_{1}{ }^{\text {ac }}$ cannot be determined with confidence as the maximum of $\chi$ " is out of the studied frequency window. The low-field increase results from the suppression by the growing $d c$ field of spinspin and spin-nucleus interactions, at the origin of the spin relaxation by breaking the degeneracy of the Kramers doublet. The fast decrease of $T_{1}{ }^{\text {ac }}$ at higher fields is characteristic of the direct relaxation, which has a strong field dependence, expected to be $\approx a B^{-4} T$ for a Kramers system. A rough estimation of it is obtained using the data in the 1-3 $\mathrm{T}$ range, at $a T=0.061(2) \mathrm{s}^{-1} T^{-n}$ and $n=1.67(10)$. This departure from the expected $B^{-4}$ behavior is indicating the likely presence of phonon bottleneck, that is known to slow down the direct relaxation process. ${ }^{30}$

The temperature dependence of $T_{1}{ }^{\text {ac }}$ was determined up to 20 $\mathrm{K}$ at two low fields, 0.05 and $0.15 \mathrm{~T}$, and on the intermediate field plateau, at $1 \mathrm{~T}$ (Figure 3 right). The fairly weak temperature dependence could be reasonably reproduced considering the direct and Raman relaxation processes using the expression $1 / T_{1}{ }^{a c}=a B^{2} T+c T^{m}$, and the value of $a$ determined at $1.8 \mathrm{~K}$. The exponents $\mathrm{m}$ are in all cases very far from the value of 9 expected for a Kramers ion, respectively $1.3,1.2$ and 0.9 at $0.05,0.15$ and $1 \mathrm{~T}$. This again is a likely consequence of phonon bottleneck effects, which are stronger in concentrated magnetic systems and are known to result in a $\approx T^{2}$ dependence. $^{31}$ Overall, the field and temperature dependences of $T_{1}{ }^{\text {ac }}$ are in line with those previously observed in other vanadyl molecular qubits ${ }^{17}$ or in $1^{\mathrm{Cu}} .^{16}$ It is interesting to note however that $T_{1}$ ac remains more than one order of magnitude longer in $1^{\text {vo }}$ than in the related $3 D$ network of $\{\mathrm{VO}(\mathrm{TCPP})\}, \mathrm{PPF}-5(\mathrm{VO}),{ }^{10}$ over the whole range of magnetic fields. And this occurs even though the volumetric spin concentration is higher in $1^{\mathrm{vo}}$, at $0.74 \mathrm{spin} \cdot \mathrm{nm}^{-3}$ vs. 0.26 spin $\cdot \mathrm{nm}^{-3}$ for PPF-5(VO). In any case, the fairly long $T_{1}{ }^{\mathrm{ac}}$ make possible reasonably long coherence times.
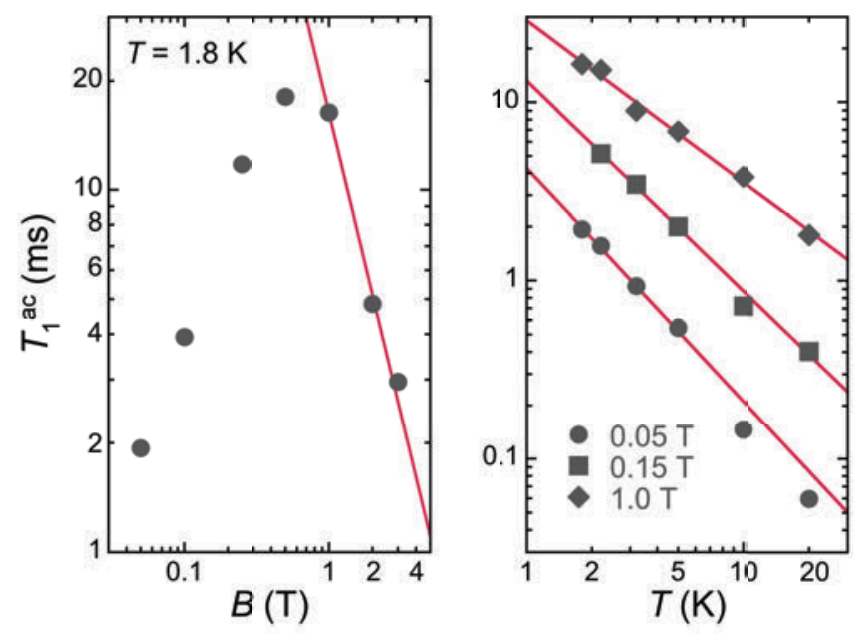

Fig. 3. Left: spin-lattice relaxation time $T_{1}^{\text {ac }}$ as a function of the $d c$ magnetic field at $1.8 \mathrm{~K}$ for $1^{\mathrm{vo}}$. The solid line is a fit of the $1-3 \mathrm{~T}$ data to $T_{1}{ }^{\text {ac }}=a B^{-n} T$ with $a T=0.061(2) \mathrm{s}^{-1} T^{-n}$ and $\mathrm{n}=1.67(10)$. Right: temperature dependence of $T_{1}^{\text {ac }}$ at $0.05,0.15$ and $1 \mathrm{~T}$ applied $d c$ fields, as indicated. Solid lines are fits to $1 / T_{1}{ }^{\mathrm{ac}}=\mathrm{a} B^{2} T+\mathrm{c} T^{\mathrm{m}}$ with $\mathrm{m}=$ $1.30(7) / 1.18(6) / 0.91(9)$ and $c=4.2(3) / 13.2(8) / 29(3) \mathrm{s}^{-1} \mathrm{~K}^{-\mathrm{m}}$ respectively for $0.05 / 0.15 / 1 \mathrm{~T}$. a is fixed at $0.033 \mathrm{~s}^{-1} \mathrm{~T}^{-2} \mathrm{~K}^{-1}$.

To evaluate the quantum coherence of the $\{\mathrm{VO}(T C P P)\}$ node in the $2 \mathrm{D}$ MOF $1^{\mathrm{VO}}$, further studies of the spin dynamics were done with Time-Domain EPR at X-band on polycrystalline

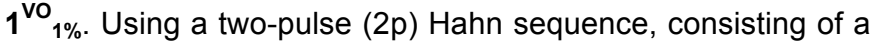


$\pi / 2$ pulse and a $\pi$ pulse separated by a varying interval $\tau$, an intense electron spin echo (ESE) is detected at any magnetic field in the CW-EPR spectrum, indicative of a measurable quantum coherence. Interestingly, the ESE remains reasonably strong at $\mathrm{RT}$, which was not the case in the $1^{\mathrm{Cu}}{ }_{1 \%}$ analogue. ${ }^{16}$ The echo-induced EPR spectrum is shown in the bottom trace of Figure 2 and indeed is in excellent agreement with the CW-EPR spectrum, being reproduced with the same Hamiltonian parameters given above (Figure S9). Inversion recovery experiments, in which the ESE signal induced through a Hahn echo sequence is measured as a function of the delay time, $t_{\mathrm{d}}$, after an initial inversion pulse, were performed in the $6-300 \mathrm{~K}$ temperature range at the most intense so-called powder line $(343.3 \mathrm{mT})$. As in the case of the copper analogue the $t_{\mathrm{d}}$ dependence of the ESE signal cannot be described by a single exponential. However, a stretched exponential dependence is able to reproduce the observed $t_{\mathrm{d}}$ dependence (see Figure S10 for data at selected temperatures and Table $\mathrm{S} 1$ for all relevant parameters estimated). Note that the stretched exponential has been written as $\exp \left\{-\left(t_{d} / \beta T_{1}^{\prime}\right)^{\beta}\right\},{ }^{32}$ where $T_{1}$ is read as a mean value of the spin-lattice relaxation time $T_{1}$. The derived temperature dependence of the mean spin-lattice relaxation time $T_{1}{ }^{\prime}$ is sketched in Figure 4. The maximum value of $10.7 \mathrm{~ms}$ at $6 \mathrm{~K}$ is in line with the values derived from ac susceptibility $(11.8 \mathrm{~ms}$ at $250 \mathrm{mT}$ and $1.8 \mathrm{~K}, 6.9 \mathrm{~ms}$ at $1 \mathrm{~T}$ and $5 \mathrm{~K}$ ). Upon increasing the temperature, $T_{1}$ ' decreases continuously and is still about $1.4 \mu \mathrm{s}$ at $300 \mathrm{~K}$. The temperature dependence of $T_{1}$ ' can be reproduced using the expression $1 / T_{1}{ }^{\prime}=a T+c T^{m}$, with $a=$ $0.0015(2) \mathrm{s}^{-1} \mathrm{~T}^{-2} \mathrm{~K}^{-1}, c=2.1(2) \times 10^{-6} \mathrm{~s}^{-1} \mathrm{~K}^{-\mathrm{m}}$ and $m=3.5(2)$. Interestingly, the exponent of the Raman relaxation term now takes a reasonable value for a Kramers ion, as expected for a magnetically-dilute solid. The direct relaxation term only becomes significant below $30 \mathrm{~K}$, Raman processes dominating the relaxation over most of the temperature range. In comparison, the related 3D material PPF-5(VO) showed a marked change of slope due to a much more dominant direct process at lower temperatures. ${ }^{10}$ Very likely this is the main reason for the longer $T_{1}$, observed in $1^{\mathrm{Vo}}{ }_{1 \%}$, about one order of magnitude at low temperatures, and still a factor 2 at RT. Another aspect resulting in the longer $T_{1}$ may be the lattice itself, and the denser packing of the $2 \mathrm{D}$ planes in $1^{\text {vo }}$ (see Figure 1). Indeed, while the square-grid planes are very similar in both materials, they are connected through long 4,4'bis-pyridine pillars in PPF-5(VO). In this respect, it is relevant to note that the $1^{\mathrm{Cu}}{ }_{1 \%}$ analogue has very similar $T_{1}$ values and temperature dependence as those of $1^{\mathrm{Vo}}{ }_{1 \%},{ }^{16}$ confirming the dominant role played by the lattice itself on $T_{1}$.

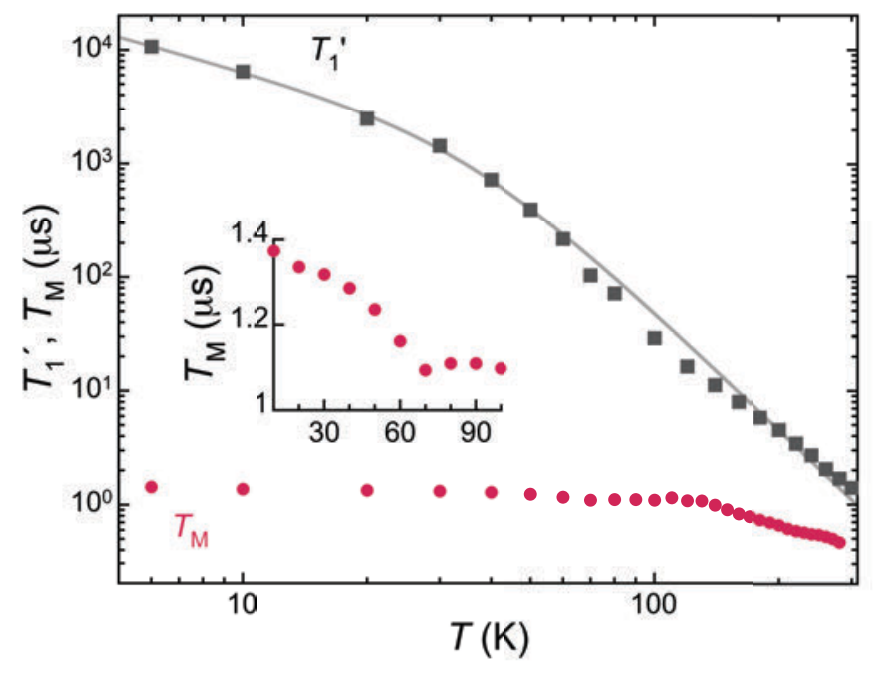

Fig. 4. Temperature dependence of the mean longitudinal relaxation time $T^{\prime}{ }_{1}$ and of the phase memory time $T_{M}$ for $1^{\text {vo }}{ }_{1 \%}$ at $343.3 \mathrm{mT}$. The grey line is a fit of the data to $1 / T_{1}^{\prime}=a T+c T^{m}$, with $a=0.0015(2) \mathrm{s}^{-1} \mathrm{~K}$ ${ }^{1}, c=2.1(2) \times 10^{-6}$ and $m=3.5(2)$. The inset shows in detail the temperature dependence of $T_{M}$ in the $10-100 \mathrm{~K}$ region.

$2 p$-ESE decay experiments were then performed to determine the temperature dependence of the phase memory time $T_{\mathrm{M}}$ in $1^{\mathrm{vo}}{ }_{1 \%}$. For this, the $\tau$-dependence of the ESE after a $2 p$ Hahn sequence was fitted to a single exponential with good agreement (see Figure S11 for data at selected temperatures and Table $\mathrm{S} 1$ for all the derived values of $T_{\mathrm{M}}$ ). The decay shows significant modulation, that could however not be reasonably modeled. This is because it appears to involve various components, contrary to the $\left[\mathrm{Cu}\left(\mathrm{H}_{4} \mathrm{TCPP}\right)\right]$ molecule in frozen solution for which the modulation was associated with one main frequency, corresponding with interaction with the neighboring ${ }^{14} \mathrm{~N}$ nuclei. ${ }^{16}$ In $1^{\mathrm{vo}}{ }_{1 \%}, T_{\mathrm{M}}$ is $1.4 \mu \mathrm{s}$ at $6 \mathrm{~K}$ and has only a very weak temperature dependence, decreasing smoothly to $0.5 \mu \mathrm{s}$ still at $280 \mathrm{~K}$ (Figure 4). A broad anomaly with slightly shorter $T_{\mathrm{M}}$ is observed consistently around $70 \mathrm{~K}$ (see inset in Figure 4). It could be associated with rotation of the phenyl rings of TCPP. ${ }^{33,34}$ The values of $T_{\mathrm{M}}$ are only slightly below those observed at low temperature for a similar isolated vanadyl porphyrin molecule ${ }^{35}$ indicating the inclusion as a node in the 2D MOF does not significantly reduce the quantum coherence. Interestingly, $T_{\mathrm{M}}$ values in $1_{1 \%}^{\mathrm{Vo}}$ are about twice those previously determined for $1^{\mathrm{Cu}}{ }_{1 \%}{ }^{16}$ This confirms the superior quantum coherence of the vanadyl $S=$ $1 / 2$ spin with respect to $\mathrm{Cu}^{\prime \prime}$, for similar environments. Even more remarkable, $T_{\mathrm{M}}$ is about four times higher in $1^{\mathrm{vo}}{ }_{1 \%}$ than in the 3D analogue material PPF-5(VO), for a similar spin concentration ( $5 \%$ dilution, but a 3 times lower volumetric porphyrin concentration, see above).$^{10}$ Most likely, this is due to the stiffer lattice resulting from the denser packing in $1^{\text {vo }}$, which results in $T_{\mathrm{M}}$ not being affected by $T_{1}$, even at RT.

To evaluate the possibility to place the vanadyl $S=1 / 2$ spin in $1^{\mathrm{vo}_{1 \%}}$ in any arbitrary superposition of states, nutation experiments were performed, both at the central more intense so called powder line, at which all orientations of the vanadyl 
spins are excited, and at the low-field crystal-like line where only a narrow set of orientations are excited (those for which the magnetic field is close to the normal to the porphyrin plane). Clear Rabi oscillations were observed, remarkably similar at both fields, except for the signal intensity (Figures 5 and S12, left). The Fourier transform of the nutation signals (Figures 5 and S12, top right) has a broad component which frequency shows a linear variation on the microwave magnetic field intensity, $B_{1}$, (Figures 5 and S12, bottom right) and corresponds to the Rabi oscillations. In addition, a $B_{1-}$ independent narrower contribution is observed, whose frequency is proportional to the applied static magnetic field and coincides with the Larmor frequency of the ${ }^{1} \mathrm{H}(14.6 \mathrm{MHz}$ at $343.3 \mathrm{mT}$ and $12.4 \mathrm{MHz}$ at $291.5 \mathrm{mT}$ ). It can thus be ascribed to Hartmann-Hahn cross-polarization with protons. ${ }^{36}$
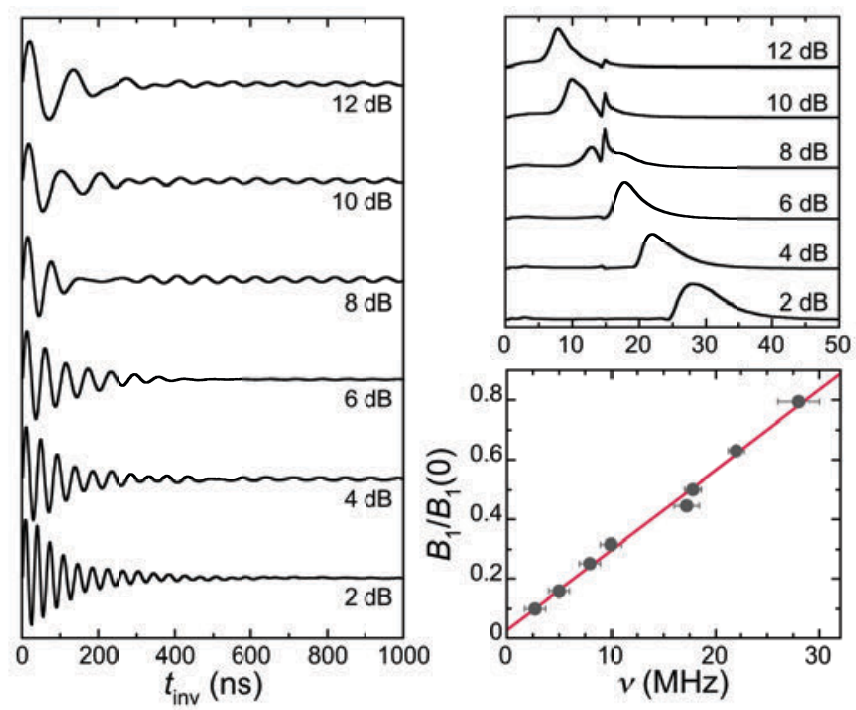

Fig. 5. Left: Rabi oscillations recorded at $80 \mathrm{~K}$ for $1_{1 \%}^{\mathrm{vo}}$ in the central powder line at $343.3 \mathrm{mT}$ and for different microwave power attenuations. Right: Fourier transform (power spectrum) of these nutation signals (top) and dependence of the Rabi frequency with the relative microwave magnetic field amplitude, $B_{1} / B_{1}(0)$ (bottom). Similar results were obtained in the crystal-like line at $291.5 \mathrm{mT}$ (see Figure S12).

Overall, the $\{\mathrm{VO}(\mathrm{TCPP})\}$ node in the diluted $2 \mathrm{D}$ MOF $1^{\mathrm{vo}}{ }_{1 \%}$ has a demonstrated ability to allow coherent spin manipulations and superior spin dynamics than its $3 \mathrm{D}$ counterpart PPF-5(VO) or its $\mathrm{Cu}^{\prime \prime}$ analogue, thus making it a viable and better spin qubit candidate. In this respect, it should be stressed that, while still modest compared with the tens of ms observed in an optimized nuclear-spin free $\mathrm{Cu}^{11}$ complex $^{8}$ or the hundreds of $\mathrm{ms}$ derived for a $\mathrm{CS}_{2}$ frozen solution of a nuclear-spin free $\mathrm{V}^{\mathrm{IV} O}$ complex, ${ }^{9}$ the phase memory times of $1^{\mathrm{vo}}{ }_{1 \%}$ are in line with values in the range $0.5-10 \mu$ s reported so far for most solid-state molecular spin qubits.

\subsection{Interfacial formation of 2D nanodomains of MOF $1^{\text {vo }}$.}

Nanodomains of isolated 2D monolayers similar to those in the structure of $1^{\mathrm{VO}}$ were fabricated at the air-water interface of a Langmuir trough. The 2D planes are formed by coordination of $\mathrm{Zn}(\mathrm{II})$ ions in the aqueous subphase by the carboxylic acid groups of [VO $\left.\left(\mathrm{H}_{4} \mathrm{TCPP}\right)\right]$ molecules expanded on the subphase surface. The method was originally reported using $\mathrm{Cu}(\mathrm{II})$ ions in the subphase, ${ }^{37}$ and has so far proven efficient with MTCPP molecules with $M$ lying in the porphyrin plane $(\mathrm{Co}, \mathrm{Cu}, \mathrm{Pd}) .{ }^{38}$ The vanadyl pointing out of the plane could a priori either be hindering or on the contrary helping the formation of good quality Langmuir film and the subsequent nanosheet formation at the interface. Langmuir isotherms of the $\left[\mathrm{VO}\left(\mathrm{H}_{4} \mathrm{TCPP}\right)\right]$ precursor expanded over water and aqueous $\mathrm{Zn}$ chloride solutions are in fact very similar to those previously observed for the [Cu( $\left.\left.\mathrm{H}_{4} \mathrm{TCPP}\right)\right]$ analogue (Figure $6 \mathrm{~A})$. In particular, the shift towards much higher areas induced by the presence of $\mathrm{Zn}(\mathrm{II})$ ions in the subphase corresponds to the formation of $2 \mathrm{D}$ nanodomains at the air-water interface. The fact the areas reached are similar likely indicates the formation of nanodomains of similar size. This is however difficult to evaluate on the sole basis of the isotherms, because multiple layers domains or aggregates may form. Interestingly, the hump present in the higher areas range in the case of $\mathrm{Cu}$, which could be related with aggregates and/or multiple layers of nanodomains, is not present in the isotherm of $\left[\mathrm{VO}\left(\mathrm{H}_{4} \mathrm{TCPP}\right)\right]$. Another difference is that the isotherm over pure water reaches a higher pressure than that of the $\mathrm{Cu}$ analogue. Altogether, this could indicate that the vanadyl group has a positive effect on the quality of the Langmuir film formed on water, which in turn could result in the MOF nanosheets films formed over $\mathrm{Zn}(\mathrm{II})$ aqueous subphase having less aggregates and/or less multiple layers of nanodomains.

These nanodomains of $2 \mathrm{D}$ planes can be transferred as mono- or multiple layers using Langmuir-Schaefer (LS) conditions. Characteristic TEM images after one sole transfer cycle show a continuous coverage of the grid carbon layer, with very weak superimposed fringes likely corresponding to a continuous MOF film (Figure 6B, top, Figure S13). Weak reciprocal points are discernible in FFTs of small areas of most TEM images (Figure 6B, middle, Figure S14), likely corresponding to lattice spacings of the metal ions in the transferred nanodomains. A statistical analysis of the corresponding distances (Figure 6B bottom, Figure S15) indeed shows that they do correspond, within experimental error and probable lattice deformation of nanodomains, to the main interplanar distances in the structure of $1^{\mathrm{Vo}}$, in particular the 020 plane, containing the $\mathrm{Zn}_{2}$ units, the 011 plane, containing the $\mathrm{V}$ atoms and in between the $\mathrm{Zn}$ atoms of the $\mathrm{Zn}_{2}$ units, and the 001 plane, also containing the $\mathrm{V}$ atoms (see Fig. S16). This supports the assumption that the 2D squaregrid structure of the $2 \mathrm{D}$ planes in $1^{\mathrm{vo}}$ is maintained in the nanodomains formed interfacially. 

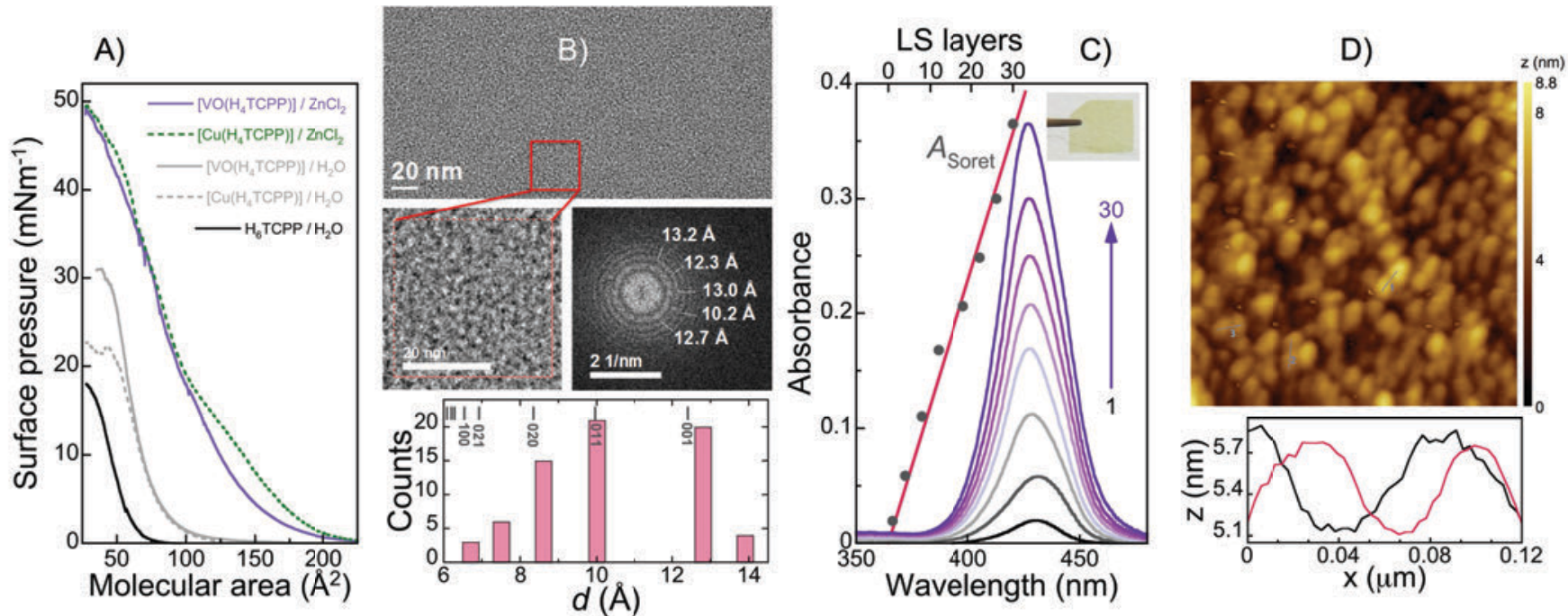

Fig. 6. A) Surface pressure-area vs. molecular area $(\pi-A)$ Langmuir isotherm for $\left[\mathrm{VO}\left(\mathrm{H}_{4} \mathrm{TCPP}\right)\right]$ spread over water and $\mathrm{ZnCl} 2$ aqueous subphases, as indicated. The corresponding isotherms for $\left[\mathrm{Cu}\left(\mathrm{H}_{4} \mathrm{TCPP}\right)\right]$ over the same subphases and for the free-base $\mathrm{H}_{6} T C P P$ over water are recalled for comparison. B) Characteristic TEM image of 1 layer of [\{VO(TCPP) $\left.\} \mathrm{Zn}_{2}\right]$ nanodomains (top), FFT (middle right) of the framed small area of the TEM image (middle left) giving rise to reciprocal points that can be ascribed to main $h k l$ interplanar distances in the structure of $1^{\text {vo }}$ (bottom, see also Figure S15). C) Progressive increase of the Soret band in the absorption spectra of successive LS deposits of 1 to 30 layers of $\left[\{\mathrm{VO}(\mathrm{TCPP})\} \mathrm{Zn}_{2}\right]$ nanodomains on Mylar, including the maximum absorbance of the Soret band as a function of the number of deposition cycle. A picture of a 30 layers LS deposit is given as inset. D) AFM topography image $\left(1.5 \times 1.5 \mu \mathrm{m}^{2}\right)$ of a 34 layers LS deposit on Mylar. Section profiles (bottom) show the film is made of domains ca. $1 \mathrm{~nm}$ in height and in the range of 30-100 nm lateral sizes.

Besides this structural characterization, XPS analysis of a thin film obtained by 34 cycles of LS transfers allows confirming the chemical identity of the deposited material. The survey spectrum and high-resolution $\mathrm{V}, \mathrm{Zn}$ and $\mathrm{N}$ spectra are virtually identical to those of bulk $1^{\text {vo }}$ (Figs. S17-18). The relative atomic ratio $\mathrm{V} / \mathrm{Zn}$ is found to be 0.35 , in reasonable agreement but below the expected value of 0.5 . While this could be indicating a small amount of unmetallated TCPP in the ultrathin films, possibly due to demetallation in solution, ${ }^{39}$ the semiquantitative nature of the technique can result in large errors for elements that are not the most abundant, as $\mathrm{V}$ here. ${ }^{40}$

In fact, the UV-Vis spectrum of a 20 layers LS deposit confirms the absence of any significant amount of unmetallated porphyrin. The Q-bands region is typical of a metallated symmetric porphyrin with one main Q-band at 555 $\mathrm{nm}$ and a weaker second band at ca. $600 \mathrm{~nm}$ (Figures S2021). Eventually, the ability to form MOF nanodomains with mixed porphyrin nodes has been verified through XPS after using a mixture of [VO $\left.\left(\mathrm{H}_{4} \mathrm{TCPP}\right)\right]$ and $\left[\mathrm{Cu}\left(\mathrm{H}_{4} \mathrm{TCPP}\right)\right]$ (Figures S17-18). This warrants that 2D MOF planes diluted with a diamagnetic node such as those in $1^{\mathrm{vo}}{ }_{1 \%}$ can also be formed interfacially.

The efficiency and repeatability of the nanodomains transfer can be followed through the absorbance at the Soret band at $426 \mathrm{~nm}$ (Figure 6C). The observed linear dependence up to at least 30 transfer cycles clearly points at similar amounts of material being transferred at each cycle. This good repeatability differs from the relative loss of efficiency previously observed in the case of $\mathrm{Cu}$ above 12 cycles. ${ }^{16}$ It is also interesting to note that absorbance after 1 cycle is lower here than with $\mathrm{Cu}$. Both effects could be associated with a better quality of the nanodomains film at the air-water interface, resulting in less multilayer nanodomains being transferred. AFM images (Figure 6D, Figures S22-23) actually support this hypothesis. First of all, rounded domains of ca. 30-100 nm lateral size are observed, thus similar to those previously formed with $\mathrm{Cu}$, and in agreement with the similar Langmuir isotherm (see above). Nevertheless, the nanodomains thickness is smaller here, at ca. $1 \mathrm{~nm}$ vs. up to 4 $\mathrm{nm}$, thus closer to the expected height of single-planes (the plane thickness in the structure of $1^{\text {vo }}$ is ca. $0.7 \mathrm{~nm}$ ). Eventually, the magnetic properties of a 40-layer deposit on Mylar are also supportive of this. Indeed, the spin surface density determined by magnetization vs. field measurements (Figure S5) indicates each transfer cycle results in the deposition of an average of ca. 1.9 molecular planes, thus much closer to 1 than the value of 3.3 found in the Cu case. ${ }^{16}$

Overall, $\left[\{\mathrm{VO}(\mathrm{TCPP})\} \mathrm{Zn}_{2}\right]$ molecular planes similar to those in the bulk solid $1^{\text {vo }}$ can be formed in-situ at the air-water interface. The 2D MOF nanodomains transferred to solid 
substrates are relatively closer to single-planes with respect to the $\mathrm{Cu}$ analogue system.

\subsection{In-situ formation of nanodomains on real device surfaces.}

The proposed hybrid quantum computing architecture mentioned in the introduction relies on coupling molecular qubits to individual photons confined in on-chip superconducting resonators. ${ }^{13}$ Thanks to the large wavelength in the microwave, a single-photon could then interact at the same time with 2 or more qubits, enabling multiple qubits operations. Experimentally however, only experiments on large ensembles, i.e. crystals, have been performed. ${ }^{41}$ Moving to single molecules is very challenging because the collective spin-photon coupling $G_{N}$ scales as $N^{1 / 2}$, with $N$ being the number of spins in the sample. Remarkable advances have been achieved in the past few years in devising novel resonator designs and/or amplification methods that enhance the sensitivity of spin resonance methods. ${ }^{25,42,43}$ Reaching the single spin limit seems to be feasible, ${ }^{13}$ but it still requires methods able to accurately control the positioning and orientation of qubits on the resonator surface. ${ }^{13}$ The photon magnetic field decreases strongly vertically from the surface, so that the molecular spin should be very close to it. However, a too intimate proximity may result in modifications of the qubit electronic levels, as observed for vanadyl phtalocyanine molecules sublimed on superconducting $\mathrm{Pb} .{ }^{15}$ Clearly, the qubit-resonator interface is crucial, and using flat nanodomains of a 2D qubit lattice may allow to adequately optimize it. Toward this goal, we have adapted the protocol previously used to form $\left[\{\mathrm{Cu}(\mathrm{TCPP})\} \mathrm{Zn}_{2}\right]$ domains on the surface of mica $^{16}$ to $\left[\{\mathrm{VO}(\mathrm{TCPP})\} \mathrm{Zn}_{2}\right]$ and the $\mathrm{Nb}$ superconducting conduction lines of a coplanar resonator. For this, a $1 \mu \mathrm{L}$ micro-droplet of aqueous $\mathrm{ZnCl}_{2}$ was first dropped on the center of a resonator with a central $14 \mathrm{~mm}$ wide line, and fabricated as described previously. ${ }^{12 a} \mathrm{~A}$ micro-droplet of the same $\mathrm{CHCl}_{3}: \mathrm{MeOH}$ solution of $\left[\mathrm{VO}\left(\mathrm{H}_{4} \mathrm{TCPP}\right)\right]$ used previously for LS transfers was then expanded atop the water local sub-phase, thus reproducing in-situ the Langmuir interface. After complete evaporation, the MOF domains formed at this interface are in principle left on the substrate surface. AFM images (Figures 7 and S24) show that small rounded domains of similar sizes as those transferred in LS conditions have indeed formed. Although the surface of the $\mathrm{Nb}$ lines is densely covered, the domains appear to be mostly isolated, with heights supportive of the formation of $\left[\{\mathrm{VO}(\mathrm{TCPP})\} \mathrm{Zn}_{2}\right]$ domains with one to few stacked molecular planes.
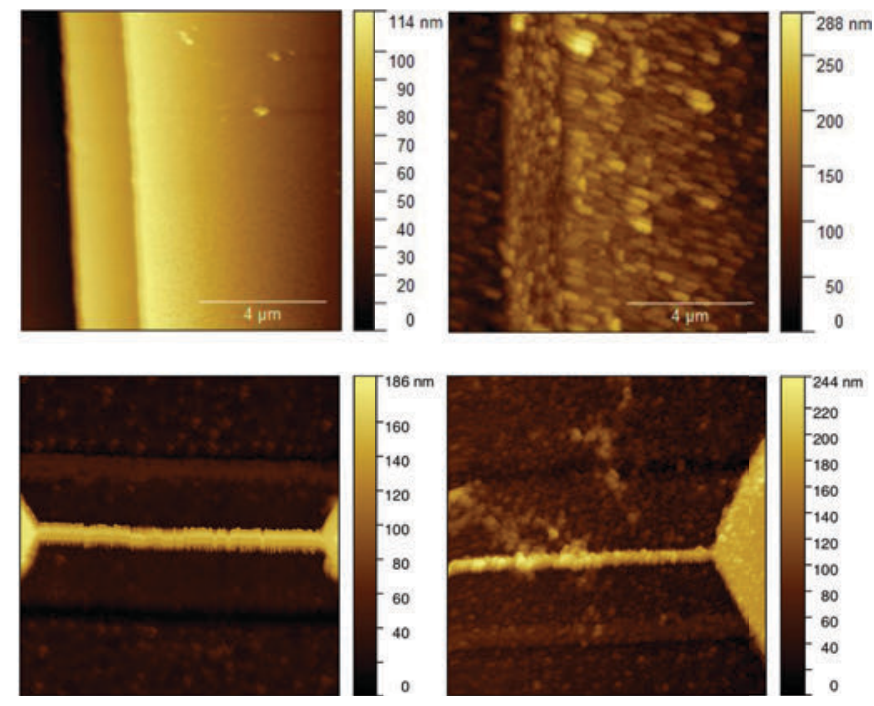

Fig. 7. AFM topography images before (left) and after (right) the in-situ formation of nanodomains of the MOF $\left[\{\mathrm{VO}(\mathrm{TCPP})\} \mathrm{Zn}_{2}\right]$, on respectively a superconducting resonator with a central $10 \mu \mathrm{m}$ line (top) and one with a $100 \mathrm{~nm}$ wide constriction in the central line (bottom). The top images are $10 \times 10 \mu \mathrm{m}^{2}$ while the bottom images are $5 \times 5 \mu \mathrm{m}^{2}$. Larger images are given in Figure S24.
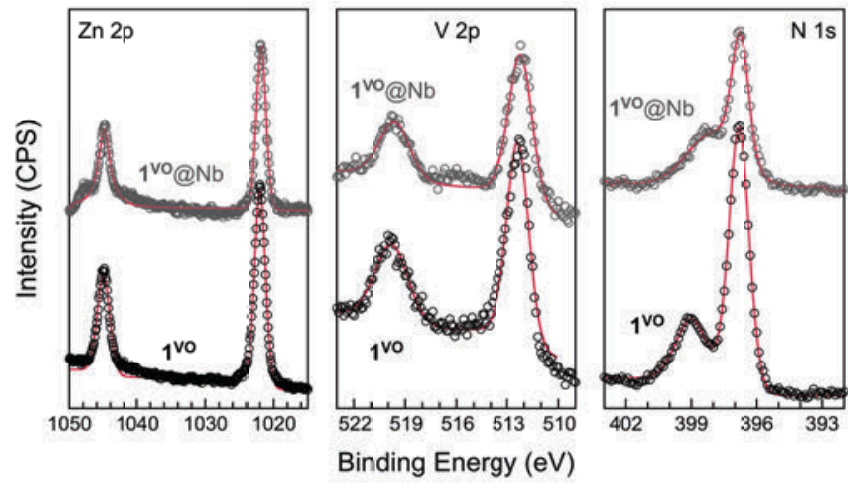

Fig. 8. X-ray photoelectron high resolution spectra of the $\mathrm{Zn} 2 \mathrm{p}$ (left), $\mathrm{V} 2 \mathrm{p}$ (middle) and $\mathrm{N} 1 \mathrm{~s}$ areas of the $\mathrm{Nb}$ resonator surface after in-situ formation of $\left[\{\mathrm{VO}(\mathrm{TCPP})\} \mathrm{Zn}_{2}\right]$ nanodomains compared to those of bulk $1^{\text {vo }}$, as indicated. The spectra are shifted for clarity. Full scales are respectively 23000, 2100 and 4500 CPS. Red lines are simulations of the spectra giving relative $\mathrm{V} / \mathrm{Zn}$ and $\mathrm{V} / \mathrm{N}$ atomic ratio of 0.43 and 0.16 for the deposit on resonator, and 0.55 and 0.16 for bulk $1^{\text {vo }}$.

The chemical composition of the domains was confirmed through XPS. It shows a survey spectrum virtually identical to those of bulk $1^{\text {vo }}$ or a 34-layers LS deposit on Mylar (Figure $\mathrm{S} 19 \mathrm{~A}$ ), and the absence of any detectable $\mathrm{Cl}$. The $\mathrm{Nb} 3 \mathrm{~d}$ bands are very weak (Figure S19B), confirming a rather dense coverage by nanodomains of the MOF. The relative $\mathrm{V} / \mathrm{Zn}$ and $\mathrm{V} / \mathrm{N}$ atomic ratios of 0.43 and 0.16 found for the deposit on the $\mathrm{Nb}$ resonator are in reasonable agreement with the values of 0.55 and 0.16 found in the case of bulk $1^{\mathrm{vo}}$. A critical aspect when grafting magnetic molecules on functional surfaces is whether they maintain their properties. ${ }^{43}$ Here, the high resolution $\vee 2 p$ spectrum is extremely similar that of bulk $1^{\text {vo }}$ (Figure 8 ), which supports the hypothesis that the vanadyl 
moiety likely maintains its electronic properties, also indicating the vanadyl groups have one sole orientation. ${ }^{44}$ The only significant modification is seen in the $\mathrm{N} 1 \mathrm{~s}$ area, in which one main band is observed at ca. $396.9 \mathrm{eV}$, similarly to bulk $1^{\mathrm{VO}}$, while a second additional band is found broader and closer to the main band in the nanodomains formed. The observation of two bands in the $\mathrm{N}$ 1s spectrum of a metalloporphyrin is an indication of the presence of supramolecular interaction(s) with the environment able to break the local symmetry. ${ }^{44}$ Here, this can reasonably be ascribed to slight variations in the interaction of the porphyrin aromatic core with the $\mathrm{Nb}$ surface. The fact that the additional band is closer to the main band for the domains formed in-situ points at only small differences and therefore to a rather homogeneous positioning of the porphyrin cores relative to the surface. In any case, the combination of the $\mathrm{Nb}$ surface roughness and the intrinsic thickness of the 2D MOF nanodomains should prevent the porphyrin from interacting strongly with the surface. This in turn likely protects the vanadyl moiety from modifications of its electronic properties, an effect often observed for isolated metalloporphyrins on metal substrates and induced by interaction with the substrate electronic states. ${ }^{15,45}$ Eventually, the same procedure was applied to a resonator with a ca. 100 $\mathrm{nm}$ wide and $4 \mathrm{~mm}$ long constriction. ${ }^{46}$ AFM images exhibit similar rounded domains along the constriction (Figure 7), demonstrating that the $\left[\{\mathrm{VO}(\mathrm{TCPP})\} \mathrm{Zn}_{2}\right]$ MOF nanodomains are still successfully formed on its reduced rounded surface.

\subsection{Microwave transmission measurements.}

Microwave transmission measurements were done for a 1.34 $\mathrm{GHz}$ resonator having its $14 \mu \mathrm{m}$ wide central transmission line covered with MOF nanodomains in a similar manner as shown in Figure 7. For comparison, the same measurements were done for a long parallelepiped single-crystal of [VO(TCPPEt)] with its elongated axis placed parallel to the transmission line (Figure S26). As our main goal is to study the molecule-tocircuit interface and how it determines the spin-photon coupling, in both cases we used concentrated (i.e. non magnetically diluted) samples in order to maximize the absorption of microwave radiation from the circuit. The field dependencies of the maximum transmission at the resonance peak, corrected for the empty resonator field dependence that arises from the influence that the magnetic field exerts on the superconducting properties of the $\mathrm{Nb}$ film (see Figure S27), are shown in Figure 9. In the single-crystal case, clear features are observed, that are also detected in the resonator frequency $\omega_{r} / 2 \pi$ and width $\kappa$ (or quality factor $Q=\omega_{r} / 2 \pi \kappa$ ), and can be associated to the coupling of photons with the vanadyl spins (Figure S28). When a spin transition becomes close to the photon energy $\hbar \omega_{r}$, this coupling leads to a resonant absorption of microwave photons, thus to a lower transmission accompanied by a decrease in $Q$, as observed. Pairs of transmission minima are unequivocally detected in the field ranges where such resonant transitions are expected for hyperfine levels corresponding to the $\mathrm{SH}$ parameters derived from the EPR characterization of $\mathbf{1}^{\mathrm{vo}}$ (see above and Figure
9). For the remaining lines, the energy splitting remains larger than $\hbar \omega_{r}$ at any field, thus these transitions cannot come into resonance with the cavity photons. Weak features are also observed in the same field ranges in the case of the MOF nanodomains, although in most cases barely above the noise level. Interestingly though, two of these features are relatively well-defined and occur at the same field ranges as the most intense transmission minima detected for the [VO(TCPPEt)] single-crystal, symmetrically in both negative and positive fields, and these features are also detected as maxima in $k$ (Figure 9). This pair of transmission minima can thus be unequivocally ascribed to resonant absorption associated with one of the hyperfine levels of the vanadyl spins in the MOF nanodomains. The collective spin-photon coupling $G_{N}$ can be derived by fitting the maxima in $\mathrm{k}$ (red lines in Figure 9) using Eq. (1), and is found to be of the order of $0.7(1) \mathrm{MHz}$ for the film and 2.3(1) $\mathrm{MHz}$ for the single crystal, at the same resonance line.

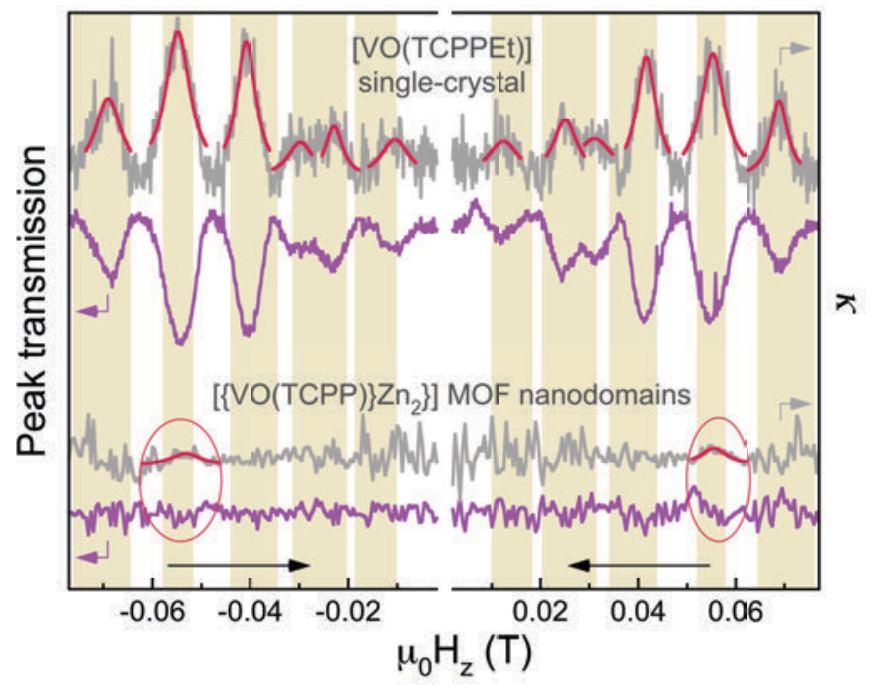

Fig. 9. Normalized resonant peak transmission $\mathrm{S}_{21}$ (purple lines) and width $\kappa$ (grey lines) of a $1.34 \mathrm{GHz}$ coplanar resonator coupled to respectively a single-crystal of [VO(TCPPEt)] (top) and [\{VO(TCPP) $\left.\} \mathrm{Zn}_{2}\right]$ MOF nanodomains formed in-situ (bottom). The data have been corrected for the empty resonator signals before normalization, and are plotted at the same scale, albeit vertically shifted for clarity (full scale is 0.7). Horizontal arrows indicate the direction of field sweep. Pairs of transmission local minima are observed in the case of the single-crystal in the field ranges for which the different spin transitions corresponding to the $\mathrm{SH}$ used to reproduce the EPR spectra of $1^{\text {vo }}$ (each for a different nuclear spin state) are expected to become resonant with the cavity photons, shown as coloured vertical background. Red circles highlight the only such pair detected unequivocally in the case of the nanodomains. Full red lines are Lorentzian fits (as expected from input-output theory for weak spin-photon coupling) of the corresponding maxima in $\kappa$, allowing to estimate the coupling strength $G_{N}$ (see Experimental section for details).

These results represent the first proof of the coupling between nanometer thick layers of vanadyl qubits and single photons trapped in coplanar on-chip cavities. At this stage it is interesting to compare the couplings found for the film and the 
crystal when they are normalized per vanadyl spin. For this, we use that $G_{N}=N^{1 / 2} G_{1}$, where $N$ is the number of spins and $\mathrm{G}_{1}$ is the (average) coupling of each spin to a single photon. Using the known values for $N\left(\approx 10^{12}\right.$ for the film, and $10^{18}$ for the crystal) we estimate $\mathrm{G}_{1}=0.5 \mathrm{~Hz}$ and $0.01 \mathrm{~Hz}$ for the film and the crystal, respectively. The strong enhancement in the film is understandable, because the coupling decreases strongly when increasing the distance of the spins to the transmission line. ${ }^{12,13}$ Along this line, it is also interesting to compare the experimental values with the optimal theoretical coupling. $G_{1}$ depends mainly on the transition matrix element, the thermal population of the levels involved and the strength of the photon magnetic field, which is spatially inhomogeneous. Numerical estimates for these quantities lead to $G_{1} \approx 0.1-0.7 \mathrm{~Hz}$, depending on the position with respect to the central transmission line (see ESI), ${ }^{12 a, 13}$ so that the value of $\mathrm{G}_{1}=0.5 \mathrm{~Hz}$ estimated for the MOF nanodomains deposit is actually close to being optimal. It is also relevant that the peak width is similar for both the single-crystal and the MOF nanodomains deposit, at ca. $90 \mathrm{MHz}$. This means that $T_{2}>10$ ns, and more importantly that the homogeneity of the vanadyl xy plane orientation is not significantly worse in the deposit than in the single-crystal. Altogether, these results show that the strategy used here allows optimizing the interface between the molecular spins and the circuit very close to the maximum allowed by the circuit design and the experimental conditions.

These first experiments also provide some hints for future improvements. The simplest one is to enhance the population of the spin ground state by reducing the temperature to below $\hbar \omega_{r} / k_{B}=0.07 \mathrm{~K}$, which then increases the thermal population of the lowest energy level involved in each transition by up to a factor 100 , and consequently $G_{1}$ by up to a factor 10 . In addition, the noise level in these experiments (that imposes a limit to the detection of $G_{N}$ of the order of 0.1-0.2 MHz), can be also improved by pre-amplifying the output signal at low $T$. Finally, the single-spin coupling $G_{1}$ can be enhanced (up to two or three orders of magnitude) by reducing the width of the central line down to $30-100 \mathrm{~nm}^{12 \mathrm{a}, 13,17}$ or, even further, by using low-inductance lump-element resonators, which help to locally enhance the micro-wave magnetic field. ${ }^{47}$ Altogether, optimizing the interface between the sample and the device that has been achieved here should enable detecting the coupling to ensembles of less than 100 molecules in the near future. The MOF nanodomains will then need to be made insitu but at the nanoscale, following nanolithographic strategies. ${ }^{13}$ As a first attempt, nano-droplet(s) of the VOTCPP node could be patterned at the constrictions using the tip of an AFM (i.e. using DIP-PEN conditions), after covering the whole surface with $\mathrm{Zn}(\mathrm{II})$ ions. We are currently exploring these aspects.

\section{Conclusions}

The work reported herein provides evidence that the 2D MOF $1^{\text {vo }}$ based on vanadyl porphyrin nodes can be made as nanodomains of one to few molecular planes after formation at an air-water interface, either through Langmuir-Schaefer transfer to a variety of substrates or in-situ on the solid surface of $\mathrm{Nb}$. The MOF vanadyl electronic spins present very long spin-lattice relaxation, with $T_{1}$ above $10 \mathrm{~ms}$ at $6 \mathrm{~K}$, and most importantly superior coherence properties, that persist until room temperature where the phase-memory time is still of the order of $0.5 \mathrm{~ms}$. The reported synthetic approach thus purveys qubit candidates of interest for the implementation of a hybrid quantum architecture. Indeed, the average coupling of the single vanadyl qubits with $\mathrm{Nb}$ superconducting resonators has been estimated to be $0.5 \mathrm{~Hz}$, very close to the optimal value for the used experimental conditions. This represents the first nanoscale measurement of the coupling of molecular qubits to a quantum cavity device, and shows that our 2D MOF nanodomains strategy allows optimizing the crucial qubitcavity interface. Designing better qubit nodes, optimizing the nanoscale formation of $2 D$ the nanodomains and improving the resonator sensitivity are current avenues of research that will hopefully enable a viable hybrid quantum computing architecture.

\section{Acknowledgements}

The authors acknowledge funding from the Spanish MINECO through projects MAT2017-86826-R (O.R., E.N., A.U.), MAT2016-78257-R (I.G., M.A.A.), and CTQ2015-64486-R (P.J.A.), as well as from the Aragón government (DGA, consolidated groups PLATON E31_17R and QMAD E09_17R) and the EU quantERA through project SUMO. M.A.A. acknowledges the support of Spanish Ministerio de Educación for a FPU grant. The authors are grateful to Dr. G. Antorrena (LMA) for his help with XPS experiments.

\section{References}

1 a) S. Lloyd, Science, 1996, 273, 1073; b) M. A. Nielsen and I. L. Chuang, Quantum Information and Quantum Computation, Cambridge University Press, Cambridge 2011; c) R. J. Hughes, D. M. Alde, P. Dyer, G. G. Luther, G. L. Morgan, M. Schauer, Contemporary Physics, 1995, 36, 149.

${ }^{2}$ T. D. Ladd, J. F. Jelezko, R. Laflamme, Y. Nakamura, C. Monroe, J. L. OBrien, Nature, 2010, 464, 45.

${ }^{3}$ M. N. Leuenberger, and D. Loss, Nature, 2001, 410, 789.

${ }^{4}$ a) M. D. Jenkins, Y. Duan, B. Diosdado, J. J. García-Ripoll, A. GaitaAriño, C. Giménez-Sainz, P. J. Alonso, E. Coronado, F. Luis, Phys. Rev. B, 2017, 95, 064423; b) R. Hussain, G. Allodi, A. Chiesa, E. Garlatti, D. Mitcov, A. Konstantatos, K. S. Pedersen, R. De Renzi, S. Piligkos, S. Carretta, J. Am. Chem. Soc., 2018, 140, 9814.

${ }^{5}$ a) F. Luis, A. Repollés, M. J. Martínez-Pérez, D. Aguilà, O. Roubeau, D. Zueco, P. J. Alonso, M. Evangelisti, A. Camón, J. Sesé, L. A. Barrios, G. Aromí, Phys. Rev. Lett., 2011, 107, 117203; b) G. Aromí, D. Aguilà, P. Gamez, F. Luis, O. Roubeau, Chem. Soc. Rev., 2012, 41, 537; c) D. Aguilà, L. A. Barrios, V. Velasco, O. Roubeau, A. Repollés, P. J. Alonso, J. Sesé, S. J. Teat, F. Luis, G. Aromí, J. Am. Chem. Soc., 2014, 136, 14215; d) A. Ardavan, A. M. Bowen, A. Fernandez, A. J. Fielding, D. Kaminski, F. Moro, C. A. Muryn, M. D. Wise, A. Ruggi, E. J. L. Mclnnes, K. Severin, G. A. Timco, C. R. Timmel, F. Tuna, G. F. S. Whitehead, R. E. P. Winpenny, npj Quantum Inf., 2015, 1, 15012; e) J. Ferrando-Soria, E. M. Pineda, A. Chiesa, A. Fernandez, S. A. Magee, S. Carretta, P. Santini, I. J. 
Vitorica-Yrezabal, F. Tuna, G. A. Timco, E. J. L. Mclnnes, R. E. P. Winpenny, Nat. Commun., 2016, 7, 11377; f) J. Salinas Uber, M. Estrader, J. Garcia, P. Lloyd-Williams, A. Sadurní, D. Dengler, J. van Slageren, N. F. Chilton, O. Roubeau, S. J. Teat, J. Ribas-Ariño, G. Aromí, Chem. Eur. J., 2017, 23, 13648; g) J. Ferrando-Soria, S. A. Magee, A. Chiesa, S. Carretta, P. Santini, I. J. Vitorica-Yrezabal, F. Tuna, G. F. S. Whitehead, S. Sproules, K. M. Lancaster, A-L. Barra, G. A. Timco, E. J. L. Mclnnes, R. E. P. Winpenny, Chem, 2016, 1, 727; h) W. Wernsdorfer and M. Ruben, Adv. Mater., 2019, 31, 1806687 .

${ }^{6}$ a) A. Ardavan, O. Rival, J. Morton, S. Blundell, A. Tyryshkin, G. A. Timco, R. E. P. Winpenny, Phys. Rev. Lett., 2007, 98, 057201; b) S. Takahashi, I. S. Tupitsyn, J. van Tol, C. C. Beedle, D. N. Hendrickson, P. C. E. Stamp, Nature, 2011, 476, 76.

${ }^{7}$ a) avoid protons through deuteration, and rotating methyl groups, see C. J. Wedge, G. A. Timco, E. T. Spielberg, R. E. George, F. Tuna, S. Rigby, E. J. L. Mclnnes, R. E. P. Winpenny, S. J. Blundell, A. Ardavan, Phys. Rev. Lett., 2012, 108, 107204 ; b) avoid nuclear spins, see refs. 8-9 and e.g. K. Bader, S. H. Schlindwein, D. Gudat, J. van Slageren, Phys. Chem. Chem. Phys., 2017, 19, 2525; use of clock transitions, see c) M. Shiddiq, D. Komijani, Y. Duan, A. Gaita-Ariño, E. Coronado, S. Hill, Nature, 2016, 531, 348; d) J. M. Zadrozny, A. T. Gallagher, T. D. Harris, D. E. Freedman, J. Am. Chem. Soc., 2017, 139, 7089

${ }^{8}$ K. Bader, D. Dengler, J. van Slageren, Nat. Commun., 2015, 5, 5304.

9 J. M. Zadrozny, J. Niklas, O. G. Poluektov, D. E. Freedman, ACS Central Sci., 2015, 1, 488.

${ }^{10}$ T. Yamabayashi, M. Atzori, L. Tesi, G. Cosquer, F. Santini, M-E. Boulon, E. Morra, S. Benci, R. Torre, M. Chiesa, L. Sorace, R. Sessoli, M. Yamashita, J. Am. Chem. Soc., 2018, 140, 12090.

${ }^{11}$ D. P. DiVicenzo, Fortschr. Phys., 2000, 48, 771.

${ }_{12}$ a) M. Jenkins, T. Hümmer, M. J. Martínez-Pérez, J. J. García-Ripoll, D. Zueco, F. Luis, New J. Phys., 2013, 15, 095007; b) A. Ghirri, C Bonizzoni, F. Troiani, N. Buccheri, L. Beverina, A. Cassinese, M. Affronte, Phys. Rev. A, 2016, 93, 063855.

${ }^{13}$ M. D. Jenkins, D. Zueco, O. Roubeau, G. Aromí, J. Majer, F. Luis, Dalton Trans., 2016, 45, 16682.

${ }^{14}$ see numerous examples in a) D. Gatteschi, A. Cornia, M. Mannini, R. Sessoli, Inorg. Chem., 2009, 48, 3408; b) A. Cornia, M. Mannini, P. Sainctavit, R. Sessoli, Chem. Soc. Rev., 2011, 40, 3076; c) N Domingo, E. Bellido, D. Ruiz-Molina, Chem. Soc. Rev., 2012, 41, 258. L. Malavolti, M. Briganti, M. Hänze, G. Serrano, I. Cimatti, G. McMurtrie, E. Otero, P. Ohresser, F. Totti, M. Mannini, R. Sessoli, S. Loth, NanoLett., 2018, 18, 7955.

${ }^{15}$ A. Urtizberea, E. Natividad, P. J. Alonso, M. A. Andrés, I. Gascón, M. Goldmann, O. Roubeau, Adv. Funct. Mater., 2018, 28, 1801695.

${ }^{16}$ a) C-J. Yu, M. J. Graham, J. M. Zadrozny, J. Niklas, M. D. Krzyniak, M. R. Wasielewski, O. G. Poluektov, D. E. Freedman, J. Am. Chem. Soc., 2016, 138, 14678; b) K. Bader, M. Winkler, J. van Slageren, Chem. Commun., 2016, 52, 3623; c) M. Atzori, L. Tesi, E. Morra, M. Chiesa, L. Sorace, R. Sessoli, J. Am. Chem. Soc., 2016, 138, 2154; d) L. Tezi, E. Lucaccini, I. Cimatti, M. Perffeti, M. Mannini, M. Atzori, E. Morra, M. Chiesa, A. Caneschi, L. Sorace, R. Sessoli, Chem. Sci., 2016, 7, 2074; e) M. Atzori, S. Benci, E. Morra, L. Tesi, M. Chiesa, R. Torre, L. Sorace, R. Sessoli, Inorg. Chem., 2018, 57, 731.

17 for reviews see a) B. J. Burnett, P. M. Barron, W. Choe, CrystEngComm, 2012, 14, 3839; b) S. Huh, S-J. Kim, Y. Kim, CrystEngComm, 2016, 18, 345.

${ }^{19}$ P. M. Barron, H-T. Son, C. Hu, W. Choe, Cryst. Growth Des., 2009, 9, 1960 .

${ }^{20}$ T. Sato, W. Mori, C. N. Kato, T. Ohmura, T. Sato, K. Yokoyama, S. Takamizawa, S. Naito, Chem. Lett., 2003, 32, 854.

${ }^{21}$ material coined PPF-1, see E-Y. Choi, C. A. Wray, C. Hu, W. Choe, CrystEngComm, 2009, 11, 553.
${ }^{22}$ material coined BNAS11, see R. Makiura, R. Usui, E. Phol, K. Prassides, Chem. Lett., 2014, 43, 1161.

${ }^{23}$ using the same conditions as in ref. 24, large crystals of [VOTCPPEt] are obtained in high yield; A. Urtizberea, O. Roubeau, P.

J. Alonso, F. Luis, I. Gimeno, unpublished results.

${ }^{24}$ W. Chen, and S. Fukuzumi, Eur. J. Inorg. Chem., 2009, 5494.

${ }^{25}$ M. D. Jenkins, U. Naether, M. Ciria, J. Sesé, J. Atkinson, C. Sánchez-Azqueta, E. del Barco, J. Majer, D. Zueco, F. Luis, Appl. Phys. Lett., 2014, 105, 162601.

${ }^{26}$ C. Eichler, A. J. Sigillito, S. A. Lyon, J. R. Petta, Phys. Rev. Lett., 2017, 118, 037701

${ }^{27}$ D. Bothner, T. Gaber, M. Kemmler, D. Koelle, R. Kleiner, S. Wüsch, M. Siegel, Phys. Rev. B, 2012, 86, 014517

${ }^{28}$ P. Bushev, A. K. Feofanov, H. Rotzinger, I. Protopopov, J. H. Cole, C. M. Wilson, G. Fischer, A. Lukashenko, A. V. Ustinov, Phys. Rev. B, 2011, 84, 060501

${ }^{29}$ S. Stoll, and A. Schweiger, J. Magn. Reson., 2006, 178, 42

${ }^{30}$ J. Soeteman, A. J. van Duyneveldt, C. L. M. Pouw, W. Breur, Physica, 1973, 66, 63.

31 J. C. Gill, Rep. Prog. Phys., 1975, 38, 91

${ }^{32}$ see eq. 2 of reference 15 , which is equivalent to the conventional expression for a stretched exponential considering $T_{1}=T_{1}^{\prime} / \beta$. In the case where the stretched exponential represents a distribution of exponential decays, it has been proven that for $\beta \leq 1, T_{1}$ corresponds to the mean value of the relaxation times, see D.C. Johnston, Phys. Rev. B, 2006, 74, 184430.

${ }^{33}$ Such effect of molecular motion on phase memory times has been reported, see J-L. Du, G. R. Eaton, S. S. Eaton, Appl. Magn. Res., 1994, 6, 373.

${ }^{34}$ Although not directly applicable here for solid-state $1^{\text {vo }}{ }_{1 \%}$, the dynamics of the rotation of meso-aryl groups in porphyrins has been studied in solution through NMR spin-lattice relaxation times, see a) $S$. S. Eaton, and G. R. Eaton, J. Am. Chem. Soc., 1975, 97, 3660; b) L. Noss, P. A. Liddell, A. L. Moore, T. A. Moore, D. Gust, J. Phys. Chem. B., 1997, 101, 458; c) C. J. Medforth, R. E. Haddad, C. M. Muzzi, N. R. Dooley, L. Jaquinod, D. C. Shyr, D. J. Nurco, M. M. Olmstead, K. M. Smith, J-G. Ma, J. A. Shelnutt, Inorg. Chem., 2003, 42, 2227.

${ }^{35}$ the $\left[\mathrm{VO}\left(\mathrm{H}_{2} \mathrm{TPP}-\mathrm{COOH}\right)\right]$ molecule has been studied both in glassy diluted solutions and doped into [ZnTPP] solid $\left(\mathrm{H}_{4} \mathrm{TPP}-\mathrm{COOH}=5,15-\right.$ bis(4-carboxyphenyl)-10,20-bis(phenyl)porphyrin; $\quad \mathrm{H}_{2}$ TPP = 5,10,15,20-tetra(phenyl)porphyrin), see J-L. Du, G. R. Eaton, S. S. Eaton, J. Magn. Res. A, 1996, 119, 240.

${ }^{36}$ S. R. Hartmann, and E. L. Hahn, Phys. Rev., 1962, 128, 2042.

${ }^{37}$ a) R. Makiura, S. Motoyama, Y. Umemura, H. Yamanaka, O. Sakata, H. Kitagawa, Nat. Mater., 2010, 9, 565; b) S. Motoyama, R. Makiura, O. Sakata, H. Kitagawa, J. Am. Chem. Soc., 2011, 133, 5640.

${ }^{38}$ a) R. Makiura, O. Konovalov, Sci. Rep., 2013, 3, 2506; b) R. Makiura, K. Tsuchiyama, O. Sakata, CrystEngComm, 2011, 13, 5538; c) R. Makiura, R. Usui, Y. Sakai, A. Nomoto, A. Ogawa, O. Sakata, A. Fujiwara, ChemPlusChem, 2014, 79, 1352; d) R. Makiura, H. Kitagawa, Y. Akita, M. Yoshimoto, J. Colloid Interface Sci., 2014, 413, 71.

${ }^{39}$ the UV-Vis spectrum of the solution (Fig. S20) is typical of vanadyl porphyrins in coordinating solvents, i.e. indicative of a mixture of metallated and de-metallated porphyrins

${ }^{40}$ In fact, both $\mathrm{V}$ and $\mathrm{Zn}$ are found to be in defective amounts with respect to $N$, with $V / N$ and $Z n / N$ ratios at 0.125 and 0.35 , to be compared with the expected values 0.25 and 0.5 .

${ }^{41}$ a) M. Mergenthaler, J. Liu, J. L. Le Roy, N. Ares, A. L. Thompson, L. Bogani, F. Luis, S. J. Blundell, T. Lancaster, A. Ardavan, G. A. D. Briggs, P. J. Leek, E. A. Laird, Phys. Rev. Lett., 2017, 119, 147701; b) C. Bonizzoni, A. Ghirri, M. Atzori, L. Sorace, R. Sessoli, M. Affronte, 
Sci. Rep., 2017, 7, 13096; c) C. Bonizzoni, A. Ghirri, M. Affronte, Adv. Phys.-X, 2018, 3, 1435305.

${ }^{42}$ a) A. Bienfait, J. J. Pla, Y. Kubo, M. Stern, X, Zhou, C. C. Lo, C. D. Weiss, T. Schnkel, M. L. W. Thewalt, D. Vion, D. Esteve, B. Julsgaard, K. Molmer, J. J. L. Morton, P. Bertet, Nature Nanotech. 2016, 11, 253; b) C. Eichler, A. J. Sigillito, S. A. Lyon, J.R. Petta, Phys. Rev. Lett., 2017, 118, 037701

${ }^{43}$ a good example of how rich and complex related studies can be is found in the case of the $\mathrm{TbPc}_{2} \mathrm{SMM}$, see $\mathrm{E}$. Moreno Pineda, $\mathrm{T}$ Komeda, K. Katoh, M. Yamashita, M. Ruben, Dalton Trans., 2016, 45, 18417.

${ }^{44}$ in the case of VOPc molecules evaporated on $\mathrm{Pb}$, two sets of $\mathrm{V} 2 \mathrm{p}$ bands were observed and ascribed to the coexistence of oxygen-up and oxygen-down orientations, thus interacting differently with the surface. See ref. 15.

${ }^{45}$ see D. M. Sarno, L. J. Matienzo, W. E. Jones Jr., Inorg. Chem., $2001,40,6308$. In the case of $1^{\mathrm{vo}}$, interplanar interactions and/or interactions with the lattice $\mathrm{dmf}$ solvent molecule are likely responsable.

${ }^{46}$ W. Auwärter, D. Écija, F. Klappenberger, J. V. Barth, Nature Chem. $2015,7,105$ and references therein. 